\title{
Electrophysiological correlates of attention networks in childhood and early adulthood
}

\author{
Alicia Abundis-Gutiérrez, Purificación Checa, Concepción Castellanos, M. Rosario Rueda* \\ Department of Experimental Psychology and Center for Research in Mind, Brain and Behavior (CIMCYC), University of Granada, Campus de Cartuja s/n, \\ 18071 Granada, Spain
}

\section{A R T I C L E I N F O}

\section{Article history:}

Received 7 August 2013

Received in revised form

10 February 2014

Accepted 14 February 2014

Available online 2 March 2014

\section{Keywords:}

Attention networks

Development

ERP

Alerting

Orienting

Executive attention

ANT

\begin{abstract}
A B S T R A C T
Attention has been related to functions of alerting, orienting, and executive control, which are associated with distinct brain networks. This study aimed at understanding the neural mechanisms underlying the development of attention functions during childhood. A total of 46 healthy 4-13-year-old children and 15 adults performed an adapted version of the Attention Network Task (ANT) while brain activation was registered with a high-density EEG system. Performance of the ANT revealed changes in the efficiency of attention networks across ages. While no differences were observed on the alerting score, both orienting and executive attention scores showed a more protracted developmental curve. Further, age-related differences in brain activity were mostly observed in early ERP components. Young children had poorer early processing of warning cues compared to 10-13-year-olds and adults, as shown by an immature auditory-evoked potential complex elicited by warning tones. Also, 4-6-year-olds exhibited a poorer processing of orienting cues as indexed by lack of modulation of the N1. Finally, flanker congruency produced earlier modulation of ERPs amplitude with age. Flanker congruency effects were delayed and more anteriorly distributed for young children, compared to adults who showed a clear modulation of the N2 in fronto-parietal channels. Additionally, interactions among attention networks were examined. Both alerting and orienting conditions modulated the effectiveness of conflict processing by the executive attention network. The Orienting $\times$ Executive networks interactions was only observed after about age 7. Results are informative of the neural correlates of the development of attention networks in childhood.
\end{abstract}

(c) 2014 Elsevier Ltd. All rights reserved.

\section{Introduction}

Attention serves as a basic set of mechanisms that underlie our awareness of the world and the voluntary regulation of thoughts and feelings (Posner, Rothbart, Sheese, \& Tang, 2007). In the past decades, Posner and colleagues (see Petersen \& Posner, 2012; Posner \& Petersen, 1990) have developed a neurocognitive model of attention, in which three differential neural networks and neuromodulators are assumed to subserve different functions. The alerting network serves the function of reaching and maintaining the state of alertness. It has been associated with frontal and parietal regions of the right hemisphere for sustained or tonic alertness, and the left hemisphere in conditions in which the level of alertness is increased by warning cues (Bekker, Kenemans, \& Verbaten, 2004; Coull, Frith, Büchel, \& Nobre, 2000). The orienting network is involved in shifting attention and selecting sensory events for preferential processing. This network comprises a

\footnotetext{
* Corresponding author. Tel.: + 34958249609.

E-mail address: rorueda@ugr.es (M.R. Rueda).
}

number of frontal and parietal structures, such as the superior parietal lobe, the temporo-parietal junction, the frontal eye fields and ventral frontal cortex that are differentially involved in topdown and bottom-up control of attention (Corbetta \& Shulman, 2002). Finally, the executive attention network is involved in control processes, such as conflict monitoring, error detection and response selection when competing alternatives are available. The anterior cingulate cortex is the main node of this network (Posner et al., 2007), which also includes areas of the lateral prefrontal cortex.

Within the framework of Posner's model of attention, an experimental paradigm, the Attention Network Task (ANT), was developed several years ago with the purpose of measuring functional efficiency of each attention network (Fan, McCandliss, Sommer, Raz, \& Posner, 2002). This task combines presentation of orienting and alerting cues (Posner, 1980) with a flanker-type task (Eriksen \& Eriksen, 1974) in order to measure alerting, orienting, and executive attention by means of time and accuracy of responses. Alerting is measured by comparing RT/Accuracy in trials with and without warning cues. Orienting of attention is examined by comparing trials with cues that direct attention to a 
location where the target will appear later on (valid cues) to trials without such cues. And, finally, executive attention is measured by comparing trials in which the target is surrounded by congruent flankers to trials with incongruent flankers. Since it was developed, the ANT has been utilized in many studies in order to characterize attention function with a wide variety of populations (e.g. Fan, Wu, Fossella, \& Posner, 2001; Jennings, Dagenbach, Engle, \& Funke, 2007; Posner et al., 2002; Rueda, Fan et al., 2004). The ANT has also been adapted to children as young as 4 years of age and some cross-sectional studies have been conducted in order to study the development of attention networks during childhood (Mezzacappa, 2004; Rueda, Fan et al., 2004; Rueda, Posner et al., 2004).

While the three functions of attention are thought to be present to some degree by the end of the first year of life, they appear to have differential developmental courses throughout childhood and adolescence (Rueda, 2013). Developmental studies addressing alertness have shown that children have greater difficulty processing warning signals compared to adults (Mezzacappa, 2004; Rueda, Fan et al., 2004). Evidence shows that young children (i.e. 5 years old) need longer warning-to-target intervals in order to benefit from warning cues and are less able to sustain alertness over time compared to older children and adults (Berger \& Posner, 2000; Morrison, 1982). On the other hand, children show a progressive increase in orienting speed to valid orienting cues during childhood (Schul, Townsend, \& Stiles, 2003). Several studies have shown that the ability to orient attention by means of peripheral as well as central cues seems to reach full maturation by age 10-11 years (Goldberg, Maurer, \& Lewis, 2001; Waszak, Li, \& Hommel, 2010). However, somewhat longer developmental courses have been observed when disengagement from an invalid location and reorienting to the valid one is needed, particularly under endogenous orienting conditions, as when long intervals between cue and target are utilized (Schul et al., 2003; Wainwright \& Bryson, 2005). Finally, there is much evidence that young children experience more difficulty than older children and adults performing tasks that involve conflict. Executive control is often measured using experimental paradigms involving conflict among stimuli, responses, or stimulus-to-response mapping, such as the flanker and Stroop-like tasks. Using a flanker task adapted to children, Rueda and colleagues have reported a significant development of the ability to suppress interference from distracting stimulation during preschool years (Rueda, Fan et al., 2004; Rueda, Posner, \& Rothbart, 2005). However, in contrast to the other attention networks, executive attention appears to develop more gradually during childhood and adolescence. Waszak et al. (2010) found that even 14-15-year olds show larger flanker interference than adults, indicating a protracted development of mechanisms related to executive control.

Numerous studies have used event-related potentials (ERP) to examine the neural basis of alerting, orienting and executive attention (see Posner, Rueda, \& Kanske, 2007), but a smaller number have addressed neural mechanisms underlying the development of these functions.

Auditory signals are frequently used to study alertness. Commonly, a series of evoked potentials can be recorded from as soon as $10 \mathrm{~ms}$ after the presentation of auditory signals (Picton, Hillyard, Krausz, \& Galambos, 1974). From about 50 to $250 \mathrm{~ms}$ following the tone, a midline-distributed series of component with different polarity (i.e., P1, N1 and P2) can be observed, which has been associated with early attentional preparation, reflecting automatic sensory activation/orientation processes (Bekker et al., 2004; Jonkman, 2006). Alerting cues also elicit a slow negative electrical brain wave, called the contingent negative variation (CNV), occurring at the interval between presentation of the cue and the imperative stimulus (Walter, Cooper, Aldridge, McCallum,
\& Winter, 1964). The CNV is considered an index of the endogenous maintenance of attentional effort during the expectancy period between the warning cue and the target (Brunia \& Damen, 1988; Gómez, Vaquero, \& Vázquez-Marrufo, 2004), and seems to have two differentiated phases. The early CNV, which emerges around $300-400 \mathrm{~ms}$ after the warning cue, appears to be related to stimulus orientation and task anticipation processes. With cue-target intervals of more than a second, a late CNV component has also been observed, which occurs prior to the imperative stimulus, and is thought to reflect motor preparation (Loveless \& Sanford, 1974).

Developmental studies have observed no differences in the modulation of early ERP components by warning cues from age 6 to adulthood (Jonkman, 2006). However, several studies using different tasks have shown that the amplitude of the CNV increases with age (Hämmerer, Li, Müller, \& Lindenberger, 2010; Jonkman, 2006; Jonkman, Lansbergen, \& Stauder, 2003; Segalowitz \& Davies, 2004). Using auditory cues and targets, Bender, Weisbrod, Bornfleth, Resch, and Oelkers-Ax (2005) found that 6-12-year-old children elicited the early CNV component but not the motor component of the CNV, which was only observed for children aged 12 years and adults.

With respect to orienting of attention, studies with adults have reported that visual targets preceded by valid spatial cues elicit brain potentials of enhanced amplitude over occipital leads, in comparison to targets presented at uncued locations (Curran, Hills, Patterson, \& Strauss, 2001; Lorenzo-López et al., 2002; Mangun, Hansen, \& Hillyard, 1986; Mangun \& Hillyard, 1991). Generally, increased P1 and reduced posterior P3 amplitudes are obtained in validly cued trials with respect to invalid ones. Modulation of the P1 is related to facilitation of early sensory processing by attention (Mangun \& Hillyard, 1987). On the other hand, modulation of the P3 has been related to stimulus evaluation processes. The higher amplitude of the P3 for invalidly cued trials appears to signal a mismatch between sensory perception and sensory-motor preparation (Digiacomo, Marco-Pallarés, Flores, \& Gómez, 2008; Gómez, Flores, Digiacomo, Ledesma, \& González-Rosa, 2008). Developmental studies of orienting attention using Posner's cueing paradigm have found that both $6-13$ years old children and adults show higher P1 amplitude on validly cued trials, whereas latencies of P3 appeared delayed for children with respect to adults under invalid conditions (Flores, Gómez, \& Meneres, 2010; Perchet \& García-Larrea, 2000).

Finally, several electrophysiological indexes have been associated with executive control processes. Congruency of distracting stimuli in a flanker task modulates the N2, a negative frontoparietal component that peaks approximately $200-400 \mathrm{~ms}$ posttarget. This effect has been related to control processes arising in the anterior cingulate cortex (van Veen \& Carter, 2002). N2 amplitude increases in incongruent trials relative to congruent trials, signaling greater effort to suppress irrelevant information in the incongruent condition. In fact, smaller N2 effect has been associated with greater efficiency of executive control over and above the effect of age (Lamm, Zelazo, \& Lewis, 2006; Stieben et al., 2007). Several developmental studies carried out with children as young as 4 years of age have observed conflictrelated amplitude modulation of ERP components. Before age 6 years, children show very weak conflict-related modulation in the latency of the N2 (Ladouceur, Dahl, \& Carter, 2007; Rueda, Posner et al., 2004). However, young children show larger conflictrelated amplitude effects compared to adults in later latencies, from about 600 to $800 \mathrm{~ms}$ post-target in anterior mid-frontal leads (Rueda, Posner et al., 2004). From about 6 to 8 years of age, the conflict-related amplitude effects are observed in more adult-like latencies, and the size of the effect appears to decrease with age (Jonkman, 2006; Lewis \& Todd, 2007). 
Later ERP components, such as the so-called Slow Positivity (SP) or Late Positive Component (LPC), have also being probed to be sensitive to conflict (Chen \& Melara, 2009; Coderre, Conklin, \& van Heuven, 2011; Larson, Kaufman, \& Perlstein, 2009; Liotti, Woldorff, Perez III, \& Mayberg, 2000; West, 2003; West \& Alain, 2000). The SP usually occurs between 500 and $600 \mathrm{~ms}$ after presentation of the target and, depending on the task difficulty and design, may appear before or after the response (Chen \& Melara, 2009; West, 2003). Modulation of the SP has also been associated with implementation of attentional control (Larson et al., 2009; Perlstein, Larson, Dotson, \& Kelly, 2006; West, 2003). However, the fact that in some studies with adults the SP effect overlaps with the time of the response (Coderre et al., 2011; Larson et al., 2009; West, 2003) suggests that SP could also reflect post-conflict rather than response selection or conflict resolution processes.

The purpose of the current study is to further understand the development of attention during childhood by studying the temporal dynamics of activation of the three attention networks by means of event-related potentials (ERPs) using the child ANT. An important advantage of the ANT is that it provides a measure of all three attention functions in the same individual in a relatively short time. It is thus a useful experimental paradigm to assess the developmental course of each attention function over childhood, providing a within-subject measure of each network. Overall, studies reviewed here suggest that the alerting, orienting and executive attention networks have different developmental trajectories throughout childhood. Alerting appears to develop mostly during early childhood, with young children showing larger alerting scores due to more delayed responses when no warning cues are presented. In relation to orienting, we expected to obtain a longer developmental trajectory than that observed by Rueda, Fan et al. (2004) due to the inclusion of invalid cues. In regard to the executive attention network, there is evidence of an important development of the ability to control attention and interference during preschool years (Rueda et al., 2005), and that this ability enhances throughout middle and late childhood (Band, van der Molen, Overtoom, \& Verbaten, 2000; Davidson, Amso, Anderson, \& Diamond, 2006). Thus, we predicted a major developmental change between early and middle childhood but further differences in efficiency of executive attention between late childhood and early adulthood.

EEG recording during performance of the ANT was used in this study with the purpose of informing about the neural mechanisms underlying the development of each attention function. Agerelated changes in electrophysiological correlates of each attention network were expected to parallel developmental courses observed with RT and accuracy results. We predicted that auditory cues would evoke early preparation responses in all participants but CNV of larger amplitude in children showing larger alerting scores. With respect to orienting, we expected to see age-related changes mostly in ERP components linked to processing of invalid cues (i.e. the P3). Finally, in relation to the executive attention network, we expected to observe modulation of the N2 and SP components by flanker interference in adults and a delayed and prolonged modulation of frontally distributed ERP components in children that parallels their greater difficulty to solve conflict.

To our knowledge, this is the first study to examine the development of attention networks in a group of children ranging from 4 to 13 years of age, and also one of the first to examine interactions among attention networks in children. Significant interactions between alerting and orienting, as well as consistent Alerting $\times$ Executive and Orienting $\times$ Executive interactions have been reported. Alerting appears to accelerate and enhance orientation of attention, whereas efficiency of executive control is impaired under conditions of invalid orientation or increased alertness (Callejas, Lupiàñez, Funes, \& Tudela, 2005; Fan et al. 2009). Recent evidence suggests that alerting influences the allocation of attention prioritizing processing of spatial information, thus leading to enhanced processing of distracting stimulation in the flanker task (Weinbach \& Henik, 2012). On the other hand, orientation to the location of the upcoming target prior to its appearance, as when valid cues are presented, raises the efficiency of executive control by facilitating focalization on the target and hence the suppression of distracters (Callejas et al., 2005).

To our knowledge, very few studies have addressed interactions between attention networks in children. Using the original version of the ANT with 4 visual cue conditions (i.e. No cue, Central cue, Spatial cue, and Double cue) and 3 flanker conditions (i.e. Congruent, Neutral and Incongruent), no interactions were observed between cue and flanker conditions in experiments involving 6 to 10 year old children (Rueda, Fan et al., 2004). However, given that adults show a consistent pattern of interactions between networks, we expected that these interactions might also be observed in children. Callejas et al. (2005) modified the original ANT in order to be able to measure interactions between the functions of alerting and orienting. They included an auditory warning cue before presentation of the visual orienting cue that precedes the target. They also included both valid and invalid orienting cues in order to examine processes of disengagement and reorienting of attention. In a recent behavioral study the child ANT was modified following the variations introduced by Callejas and colleagues to study the development of attention networks and their interactions from age 6 to 12 years (Pozuelos, Paz-Alonso, Castillo, Fuentes, \& Rueda, under review). Results revealed alerting $\times$ orienting as well as orienting $\times$ executive attention interactions that were present along the age range studied. Also, the state of alertness affected accuracy of conflict processing, but the direction of this interaction changed with age. For the purpose of the current study, we used the same task as Pozuelos et al. and aimed at extending their results by using a sample of participants with a wider age-range and analyzing brain mechanisms underlying interactions among networks. We hypothesized that younger children's executive control efficiency would be more hampered on conditions that impose greater demands of suppression of distracting information, i.e. conditions conveying higher alertness and less focused orientation. Thus, we expected to observe Alerting $\times$ Executive as well as Orienting $\times$ Executive interactions, and aimed at exploring second order interactions with age. Further, in case interactions between networks would be found at the level of the response, these should also be noticeable at the brain function level. Hence, we expected to find modulation of conflict-related N2 and SP effects by alerting and orienting conditions for those age groups in which interactions would be observed at the behavioral level of analysis.

\section{Materials and method}

\subsection{Participants}

A total of 46 children and 15 adults (mean age: 23.6 years; SD: 2.6 years) participated in the study. Children were divided in three groups: 4-6-year olds ( $n=16$ mean age $=4.96$ years, $\mathrm{SD}=0.87$ months), $7-9$-year olds $(n=15$, mean age $=8.25$ years; SD: 12 months) and $10-13$-year olds $(n=15$, mean age $=10.8$ years, $\mathrm{SD}=17.2$ months). Children's caregivers were contacted by phone and invited to participate in the study. They were part of a database of families who participated in prior studies and expressed their wiliness to participate in future studies. Adult participants were under and post-graduate students recruited through the website of the Psychology Department of the University of Granada Participants had normal or corrected-to-normal sensory capacities, no history of chronic illness and/or psychopathologies and no known neurological disorders, ADHD, ASD or Learning Disabilities, as informed by their caregivers. Participation in the study was voluntary, and both parent of the children and adults gave written consent prior to participation. 


\subsection{Procedure}

Participants were tested individually at the Cognitive Neuroscience laboratory of the University of Granada. At arrival, participants were informed of the general procedure of the session and were given a few minutes to get comfortable in the lab setting before starting. Participants were fitted with the 128 channels Geodesic Sensor Net (www.egi.com) and were verbally informed of the instructions to complete the task. The duration of the session was $1 \mathrm{~h}$ approximately, including time for instructions and breaks between blocks. Young children received stickers between blocks of trials as incentives to stay motivated and complete the task. The experimenter was present in the testing room throughout the session with children of all ages, but did not provide feedback to participants apart from encouragement to complete the task during breaks. A T-shirt with the logo of the lab was offered to participants at the end of the session in appreciation for their participation in the study.

\subsection{Experimental task}

All participants performed an adapted version of the child ANT (Rueda, Fan et al., 2004). The sequence of events in each trial is displayed in Fig. 1. Each trial started with a fixation point of variable duration, which was randomly selected between 600 and $1200 \mathrm{~ms}$. In half of the trials, a $2000 \mathrm{~Hz}$ tone was presented as alerting cue during $100 \mathrm{~ms}$. Subsequently, an orienting cue, consisting of an asterisk, could appear above or below the fixation point for $100 \mathrm{~ms}$. The asterisk only appeared in two-thirds of the trials, and no cue was displayed in the other one-third of trials. When presented, the orienting cue appeared in the same location of the subsequent target (valid cue) in half of the trials, and in the opposite (invalid cue) location in the remaining half. Finally, a horizontal row of five line drawing fish was presented above or below the fixation point. Fish flanking the one in the middle pointed to either the same (congruent trials) or the opposite (incongruent trials) direction as the central fish (target). Half of the trials were congruent, and half incongruent. Participants were asked to indicate the direction of the central fish by pressing the right or left bottom in a response box as rapidly and accurately as possible. The target display was presented until a response was made or up to $2500 \mathrm{~ms}$. A feedback was provided $500 \mathrm{~ms}$ after the response, which consisted of an animation of the middle fish, showing it happy (blowing bubbles) and saying "yes" for correct responses, or sad (tears coming down the eye) and saying "no" for incorrect or missed trials. All stimuli were presented over a cyancolored background. Adults completed eight blocks of 36 trials each plus 12 practice trials. Children completed four blocks of 36 trials each, preceded by 12 practice trials. The practice block was ran as many times as necessary until it was clear that the instructions were fully understood. In order to make the task friendly for children, they were told that the middle fish was hungry and they were to feed it by pressing the appropriate button.

\subsection{Behavioral data analysis}

Performance of the ANT allows calculation of scores for each attention network. Three subtractions were performed in order to calculate the alerting, orienting and executive attention scores for each participant using the median RTs per condition. The alerting score was calculated by subtracting the median RT for tone from the median RT for the no-tone condition. The orienting score was obtained by subtracting median RT for the valid cue from the invalid cue condition. Finally, the executive attention score was obtained by subtracting median RTs for congruent trials from median RTs for incongruent trials. Age differences for each network score were assessed with one-way ANOVAs. Additionally, sets of mixed ANOVAs including Age-Group as between-subject factor and Alerting Cue (no-tone vs. Tone), Orienting Cue (valid, invalid and no-cue) and Flanker Congruency (congruent vs. incongruent) with median RT and percentage of commission errors as dependent measures were also conducted. In addition to information about the main effects of each factor, mixed ANOVAs allowed examination of interactions between attention networks, as well as second-order interactions involving Age Group.

\subsection{EEG acquisition and ERP processing}

EEG was recorded using a 128-channel Geodesic Sensor Net 4.2 (GSN; Tucker, Liotti, Potts, Russell, \& Posner, 1993) and processed using Net Station 4.3 software. The EEG signal was digitized at $250 \mathrm{~Hz}$. The EEG signal was acquired using a 100$0.01 \mathrm{~Hz}$ band pass filter. Impedances for each channel were kept below $50 \mathrm{k} \Omega$ during recording. Channels with larger impedances at recording were noted and discarded for processing later on. The average impedance during recording of channels included in further analyses was $23.17 \mathrm{k} \Omega$. Continuous EEG data were filtered by using a finite impulse response (FIR) band pass filter with $0.3 \mathrm{~Hz}$ highpass and $20 \mathrm{~Hz}$ low-pass cutoffs (Passband gain: 99.0\% ( $-0.1 \mathrm{~dB}$ ), stopband gain: $1.0 \%(-40.0 \mathrm{~dB})$, rolloff: $0.29 \mathrm{~Hz})$. Then, data were segmented into alerting cuelocked ( $-200 \mathrm{~ms}$ to $800 \mathrm{~ms}$ around presentation of the alerting cue) and targetlocked ( $200 \mathrm{~ms}$ pre-target to $1000 \mathrm{~ms}$ post-target) epochs. Segmented files were scanned for artifacts with the Artifact Detection NS tool using a threshold of $70 \mu \mathrm{V}$ (adults) or $100 \mu \mathrm{V}$ (children) for eye movements and $70 \mu \mathrm{V}$ (adults) or $120 \mu \mathrm{V}$ (children) for eye blinks. Bad channels were rejected and replaced by interpolation from neighbors' channels. Segments containing more than 20 bad channels, eye blinks or eye movements were excluded from further processing. Data for each trial were also visually inspected for each participant. Artifact-free segments for correct responses were averaged across conditions and participants within each age group, and re-referenced to the average of all channels. A per-subject criterion of a minimum of 16 artifact-free segments per experimental condition and 50 good segments among the correctly responded trials was established in order to be included in the grand-average for each age group. The $200 \mathrm{~ms}$ preceding the target or alerting cue served as baseline in both alerting cue- and target-locked segments. Event-related potentials (ERP) with the experimental conditions of interest for each attention network were built and plotted in the same graph for each age group.

Two main strategies were used to analyze within and between-groups effects of experimental conditions in the ERP data. First, peak amplitude values of the ERP components of interest were extracted for each condition and used to carry out analysis of variance with Age Group as between-subjects factor and the conditions of interests as the within-subject factor. These ANOVAs informed about differences in brain potentials relevant for each attention network, and allowed to examine differences between age groups in those effects. Second, in order to examine

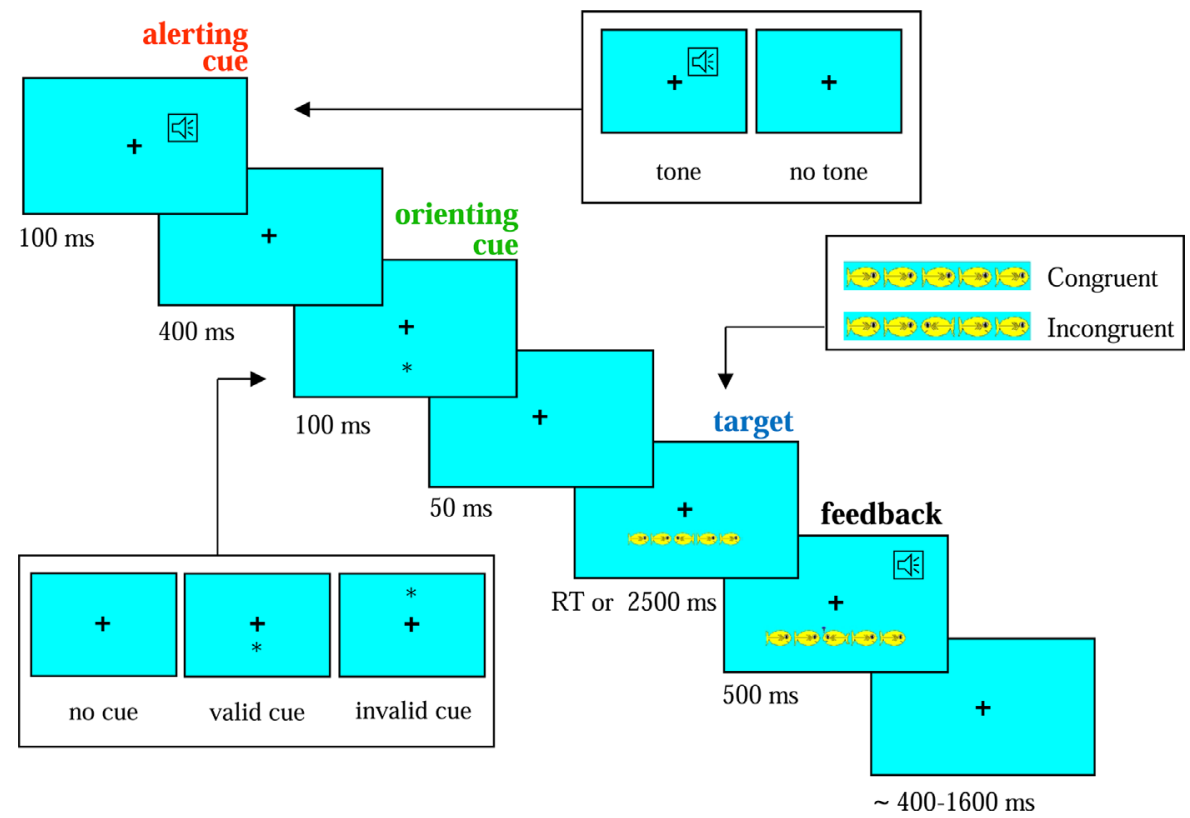

Fig. 1. Structure of the task utilized in the study. 
differences between conditions along the ERP components of interest, we computed amplitude differences at each time point along the entire epoch by mean of pair-wise t-tests. Modulations of amplitudes by experimental manipulations can occur along the entire epoch and not only in the peaks of the components. Analyses with $t$-tests inform about the extension of those modulations in the time domain. In all ERPs figures, the shadowed areas between ERP waves show the sections of the segments in which amplitude differences between conditions were significant ( $p<0.05$; uncorrected for multiple comparisons) as analyzed with two-tailed dependent-samples $t$-tests $(t>2.145(n=15)$ for the 7-9, 10-13 and adult groups, and $t>2.160(n=14)$ for the 4-6 years old group). Topographic maps illustrate the distribution over the scalp of the significant amplitude differences between experimental conditions at particular segment times.

\section{Results}

\subsection{Behavioral results}

Omission errors were virtually inexistent (only one omission error committed by one participant), thus accuracy of performance was analyzed with percentage of commission errors. Two participants from the 4-6 years-old group were excluded for further processing due to a high percentage of commission errors (above $40 \%$ ). Means of the median RT for correct responses and percentage of commission errors for each condition and age group are presented in Tables 1 and 2, respectively.

The network scores for each age group are summarized in Table 3. Results from one-way ANOVAs with the networks scores showed no significant effect of Age for the alerting score $(F(3,55)=$ 1.19; $p=0.32)$, but significant effects for the orienting $(F(3,55)=$ 3.66; $\left.p<0.05, \eta_{\mathrm{p}}^{2}=0.17\right)$ and executive $(F(3,55)=6.02 ; p<0.01$, $\left.\eta_{\mathrm{p}}^{2}=0.25\right)$ networks scores. Planned contrasts showed no significant differences between groups of children in the orienting score (except for a marginal difference between 4-6- and 7-9-year-olds, $F(1,55)=2.94 ; p=0.09)$, but $10-13$ as well as $7-9$ year-olds differed from adults $(F(1,55)=6.29 ; p<0.05, F(1,55)=9.24 ; p<0.001$, respectively). Regarding the executive network, we obtained a significant linear reduction of executive attention scores with age $(F(1,55)=17.7 ; p<0.001)$. Additionally, planned contrasts showed that adults differed significantly from 4-6-year-olds $(F(1,55)=$ 17.47; $p<0.001)$ and 7-9-year-olds $(F(1,55)=5.98 ; p<0.05)$, and marginally from $10-13$-year-olds $(F(1,55)=2.85 ; p=0.09)$. Also, 4-6 year-olds differed from $10-13(F(1,55)=6.36 ; p<0.05)$ and marginally from 7-9-year-olds $(F(1,55)=3.16 ; p=0.08)$.

Separate 4 (Age Group) $\times 2$ (Alerting Cue: no-tone vs. tone $) \times$ 3 (Orienting Cue: invalid, valid, and no-cue) $\times 2$ (Flanker Congruency: congruent vs. incongruent) ANOVAs with median RTs and percentage of commission errors as dependent measures were carried out. In both analyses, main effects of all four factors were significant. The main effect of Age Group was significant for both RT and commission errors, indicating a linear reduction of response time $\left(F(3,55)=79.73 ; p<0.001, \eta_{\mathrm{p}}^{2}=0.81\right)$ with age, whereas with percentage of errors the effect was due to a significant difference between the youngest group of children and the rest of the groups $(F(1,55)=$ 3.85; $\left.p<0.05, \eta_{\mathrm{p}}^{2}=0.17\right)$. The main effect of Alerting Cue was significant with both RT $\left(F(1,55)=16.62 ; p<0.001, \eta_{\mathrm{p}}^{2}=0.23\right)$ and percentage of commission errors $\left(F(1,55)=4.71 ; p<0.05, \eta_{\mathrm{p}}^{2}=0.08\right)$.

Table 2

Percentage of commission errors (SDs) per age group and task condition.

\begin{tabular}{|c|c|c|c|c|c|c|c|c|}
\hline \multirow[t]{2}{*}{ Age } & \multirow{2}{*}{$\begin{array}{l}\text { Total \% } \\
\text { errors }\end{array}$} & & \multicolumn{3}{|l|}{ No tone } & \multicolumn{3}{|l|}{ Tone } \\
\hline & & & Invalid & $\begin{array}{l}\text { No } \\
\text { cue }\end{array}$ & Valid & Invalid & $\begin{array}{l}\text { No } \\
\text { cue }\end{array}$ & Valid \\
\hline $4-6$ years & $\begin{array}{l}9.7 \\
(14.2)\end{array}$ & $\begin{array}{l}\text { Cong } \\
\text { Incong }\end{array}$ & $\begin{array}{l}5.66 \\
(1.8) \\
10.27 \\
(2.4)\end{array}$ & $\begin{array}{l}9.82 \\
(1.8) \\
9.38 \\
(2.2)\end{array}$ & $\begin{array}{l}9.82 \\
(2.0) \\
6.99 \\
(1.8)\end{array}$ & $\begin{array}{l}8.93 \\
(2.3) \\
9.52 \\
(2.7)\end{array}$ & $\begin{array}{l}11.01 \\
(2.4) \\
11.76 \\
(2.6)\end{array}$ & $\begin{array}{l}9.23 \\
(1.9) \\
12.35 \\
(2.7)\end{array}$ \\
\hline $7-9$ years & $\begin{array}{l}3.2 \\
(5.4)\end{array}$ & $\begin{array}{l}\text { Cong } \\
\text { Incong }\end{array}$ & $\begin{array}{l}1.11 \\
(1.8) \\
7.22 \\
(2.3)\end{array}$ & $\begin{array}{l}1.67 \\
(1.7) \\
2.50 \\
(2.2)\end{array}$ & $\begin{array}{l}1.67 \\
(2.0) \\
2.78 \\
(1.7)\end{array}$ & $\begin{array}{l}2.64 \\
(2.2) \\
8.75 \\
(2.6)\end{array}$ & $\begin{array}{l}1.53 \\
(2.3) \\
4.44 \\
(2.5)\end{array}$ & $\begin{array}{l}0.00 \\
(1.8) \\
4.30 \\
(2.6)\end{array}$ \\
\hline $\begin{array}{l}\text { 10-13 } \\
\text { years }\end{array}$ & $\begin{array}{l}2.2 \\
(4.2)\end{array}$ & $\begin{array}{l}\text { Cong } \\
\text { Incong }\end{array}$ & $\begin{array}{l}2.78 \\
(1.8) \\
4.44 \\
(2.3)\end{array}$ & $\begin{array}{l}0.56 \\
(1.7) \\
1.67 \\
(2.2)\end{array}$ & $\begin{array}{l}1.11 \\
(2.0) \\
1.11 \\
(1.7)\end{array}$ & $\begin{array}{l}0.56 \\
(2.2) \\
6.67 \\
(2.6)\end{array}$ & $\begin{array}{l}0.00 \\
(2.3) \\
2.78 \\
(2.5)\end{array}$ & $\begin{array}{l}1.11 \\
(1.8) \\
4.17 \\
(2.6)\end{array}$ \\
\hline Adults & $\begin{array}{l}2.9 \\
(3.8)\end{array}$ & $\begin{array}{l}\text { Cong } \\
\text { Incong }\end{array}$ & $\begin{array}{l}1.67 \\
(1.8) \\
6.67 \\
(2.3)\end{array}$ & $\begin{array}{l}0.42 \\
(1.7) \\
2.92 \\
(2.2)\end{array}$ & $\begin{array}{l}0.00 \\
(2.0) \\
3.33 \\
(1.7)\end{array}$ & $\begin{array}{l}1.25 \\
(2.2) \\
8.75 \\
(2.6)\end{array}$ & $\begin{array}{l}0.83 \\
(2.28) \\
5.42 \\
(2.52)\end{array}$ & $\begin{array}{l}1.67 \\
(1.8) \\
1.67 \\
(2.59)\end{array}$ \\
\hline
\end{tabular}

Table 3

Attention network scores in ms (SD) per age group.

\begin{tabular}{lllc}
\hline & Alerting & Orienting & Executive \\
\hline $\mathbf{4 - 6} \mathbf{~ y r}$ & $36(68)$ & $53(86)$ & $124(81)$ \\
$\mathbf{7 - 9} \mathbf{~ y r}$ & $37(40)$ & $87(57)$ & $92(48)$ \\
$\mathbf{1 0 - 1 3} \mathbf{~ y r}$ & $12(28)$ & $77(28)$ & $78(21)$ \\
Adults & $17(32)$ & $28(16)$ & $48(24)$ \\
\hline
\end{tabular}

Table 1

Mean of median RT (SDs) per Age Group and task condition.

\begin{tabular}{|c|c|c|c|c|c|c|c|c|}
\hline \multirow[t]{2}{*}{ Age } & \multirow[t]{2}{*}{ Median RT } & & \multicolumn{3}{|c|}{ No tone } & \multicolumn{3}{|l|}{ Tone } \\
\hline & & & Invalid & No cue & Valid & Invalid & No cue & Valid \\
\hline \multirow[t]{2}{*}{ 4-6 years } & \multirow[t]{2}{*}{1060 (210) } & Cong & $\begin{array}{l}983 \\
(338)\end{array}$ & $\begin{array}{l}1077 \\
(208)\end{array}$ & $\begin{array}{l}982 \\
(181)\end{array}$ & $\begin{array}{l}1002 \\
(187)\end{array}$ & $\begin{array}{l}928 \\
(154)\end{array}$ & $\begin{array}{l}942 \\
(190)\end{array}$ \\
\hline & & Incong & $\begin{array}{l}1143 \\
(182)\end{array}$ & $\begin{array}{l}1077 \\
(130)\end{array}$ & $\begin{array}{l}1086 \\
(311)\end{array}$ & $\begin{array}{l}982 \\
(197)\end{array}$ & $\begin{array}{l}1159 \\
(238)\end{array}$ & $\begin{array}{l}1002 \\
(348)\end{array}$ \\
\hline \multirow[t]{2}{*}{ 7-9 years } & \multirow[t]{2}{*}{736 (147) } & Cong & $\begin{array}{l}706 \\
(167)\end{array}$ & $\begin{array}{l}743 \\
(175)\end{array}$ & $\begin{array}{l}684 \\
(148)\end{array}$ & $\begin{array}{l}705 \\
(150)\end{array}$ & $\begin{array}{l}672 \\
(116)\end{array}$ & $\begin{array}{l}623 \\
(97)\end{array}$ \\
\hline & & Incong & $\begin{array}{l}844 \\
(148)\end{array}$ & $\begin{array}{l}789 \\
(135)\end{array}$ & $\begin{array}{l}743 \\
(164)\end{array}$ & $\begin{array}{l}838 \\
(141)\end{array}$ & $\begin{array}{l}790 \\
(171)\end{array}$ & $\begin{array}{l}688 \\
(157)\end{array}$ \\
\hline \multirow[t]{2}{*}{ 10-13 years } & \multirow[t]{2}{*}{$582(97)$} & Cong & $\begin{array}{l}558 \\
(93)\end{array}$ & $\begin{array}{l}574 \\
(89)\end{array}$ & $\begin{array}{l}520 \\
(91)\end{array}$ & $\begin{array}{l}558 \\
(94)\end{array}$ & $\begin{array}{l}548 \\
(99)\end{array}$ & $\begin{array}{l}513 \\
(79)\end{array}$ \\
\hline & & Incong & $\begin{array}{l}654 \\
(90)\end{array}$ & $\begin{array}{l}634 \\
(116)\end{array}$ & $\begin{array}{l}574 \\
(81)\end{array}$ & $\begin{array}{l}657 \\
(74)\end{array}$ & $\begin{array}{l}632 \\
(170)\end{array}$ & $\begin{array}{l}561 \\
(85)\end{array}$ \\
\hline \multirow[t]{2}{*}{ Adults } & \multirow[t]{2}{*}{$426(57)$} & Cong & $\begin{array}{l}403 \\
(49)\end{array}$ & $\begin{array}{l}435 \\
(83)\end{array}$ & $\begin{array}{l}385 \\
(59)\end{array}$ & $\begin{array}{l}397 \\
(45)\end{array}$ & $\begin{array}{l}41 \\
(55)\end{array}$ & $\begin{array}{l}380 \\
(44)\end{array}$ \\
\hline & & Incong & $\begin{array}{l}463 \\
(67)\end{array}$ & $\begin{array}{l}466 \\
(51)\end{array}$ & $\begin{array}{l}439 \\
(72)\end{array}$ & $\begin{array}{l}463 \\
(46)\end{array}$ & $\begin{array}{l}452 \\
(53)\end{array}$ & $\begin{array}{l}420 \\
(57)\end{array}$ \\
\hline
\end{tabular}


The main effect of Orienting Cue was also significant with both RT $\left(F(2,110)=19.70 ; p<0.001, \eta_{\mathrm{p}}^{2}=0.26\right)$ and commission errors $\left(F(2,110)=6.29 ; p<0.01, \eta_{\mathrm{p}}^{2}=0.10\right)$. Finally, the main effect of Flanker Congruency was significant with RT $(F(1,55)=122.53 ; p<0.001$, $\left.\eta_{\mathrm{p}}^{2}=0.69\right)$ as well as with percentage of errors $(F(1,55)=39.47$; $p<0.001, \eta_{\mathrm{p}}^{2}=0.42$ ). Additionally, Age Group interacted with Flanker Congruency, an interaction that was significant with RT $(F(3,55)=$ 3.94; $p<0.05, \eta_{\mathrm{p}}^{2}=0.18$ ) but only marginal with error percentage $\left(F(3,55)=2.23 ; p=0.09, \eta_{\mathrm{p}}^{2}=0.11\right)$. Also, a significant Alerting $\times$ Flanker Congruency interaction was found in the RT ANOVA $(F(1,55)=$ $\left.4.50 ; p<0.05, \eta_{\mathrm{p}}^{2}=0.08\right)$, which was only marginal $(F(1,55)=3.15$; $\left.p=0.08, \eta_{\mathrm{p}}^{2}=0.05\right)$ in the commission errors ANOVA. In order to further explore this interaction, we conducted a second ANOVA in which only trials without orienting cues were considered, because orienting cues convey spatial as well as warning information about the upcoming target, which is likely to affect the preparation effect of alerting cues (see Callejas et al., 2005). In this second ANOVA, the Alerting $\times$ Flanker Congruency interaction remained significant $(F$ $\left.(1,55)=7.05 ; p<0.05, \eta_{\mathrm{p}}^{2}=0.11\right)$, and the second-order interaction of Alerting $\times$ Flanker Congruency $\times$ Age did not reach statistical significance $(F(3,55)=2.06 ; p=0.12)$. A graph depicting means of median RTs in each alerting and flanker congruency condition for each age group is presented in Fig. 2. As shown in the figure, the younger groups of children showed stronger modulation of the flanker congruency effect by alerting conditions $(F(1,13)=3.03 ; p=0.10$, $\eta_{\mathrm{p}}^{2}=0.19 ; F(1,14)=5.81 ; p<0.05, \eta_{\mathrm{p}}^{2}=0.29$, respectively for $4-6$ - and 7-9-year-olds) while the effect was not-significant for 10-13-yearolds $(F(1,14)=1.08 ; p=0.32)$ or adults $(F<1)$.

In addition, a significant Orienting $\times$ Flanker Congruency $\times$ Age interaction was obtained in the RT ANOVA. This interaction remained significant $\left(F(3,55)=3.72 ; p<0.05, \eta_{\mathrm{p}}^{2}=0.17\right)$ when trials with no orienting cue were not considered in the analysis, thus including only valid and invalid cues (96 trials for children and 192 trials for adults, from which half (48/96) were validly cued). This interaction, represented in Fig. 3, indicated that the flanker interference effect was larger under the invalid compared to the valid orienting cue condition for all age groups except the youngest children who showed equivalent interference effects under the two orienting cue conditions $\left(F(1,14)=5.6 ; p<0.05, \eta_{\mathrm{p}}^{2}=0.29, F(1,14)=40.85 ; p<0.001, \eta_{\mathrm{p}}^{2}=0.74, F\right.$ $(1,14)=6.50 ; p<0.05, \eta_{\mathrm{p}}^{2}=0.32$, and $F(1,13)=1.6 ; p=0.22, \eta_{\mathrm{p}}^{2}=0.11$ respectively for adults, 10-13-, 7-10- and 4-6-year olds).

\subsection{ERPs analyses}

Measures of amplitudes for each ERP component, condition and Age Group are presented in Table 4. Different ANOVAs were conducted with these amplitude data. Results of these various ANOVAs are presented bellow.

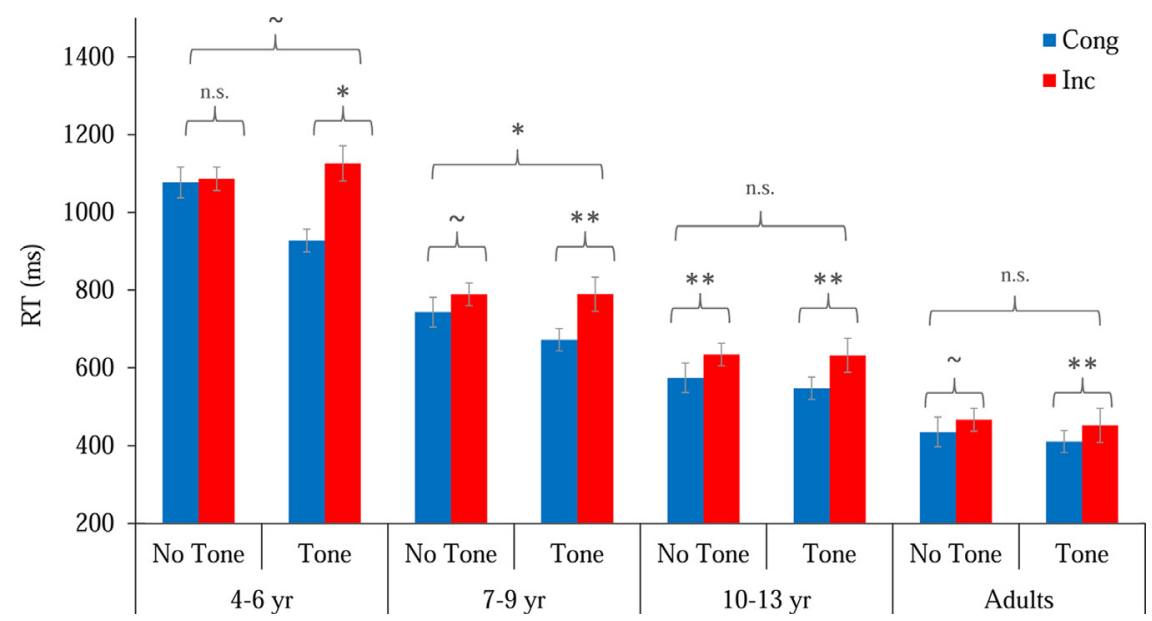

Fig. 2. Graphical representation of mean RTs (in ms) per flanker congruency (Cong: congruent; Inc: incongruent) and alerting conditions in function of age group.

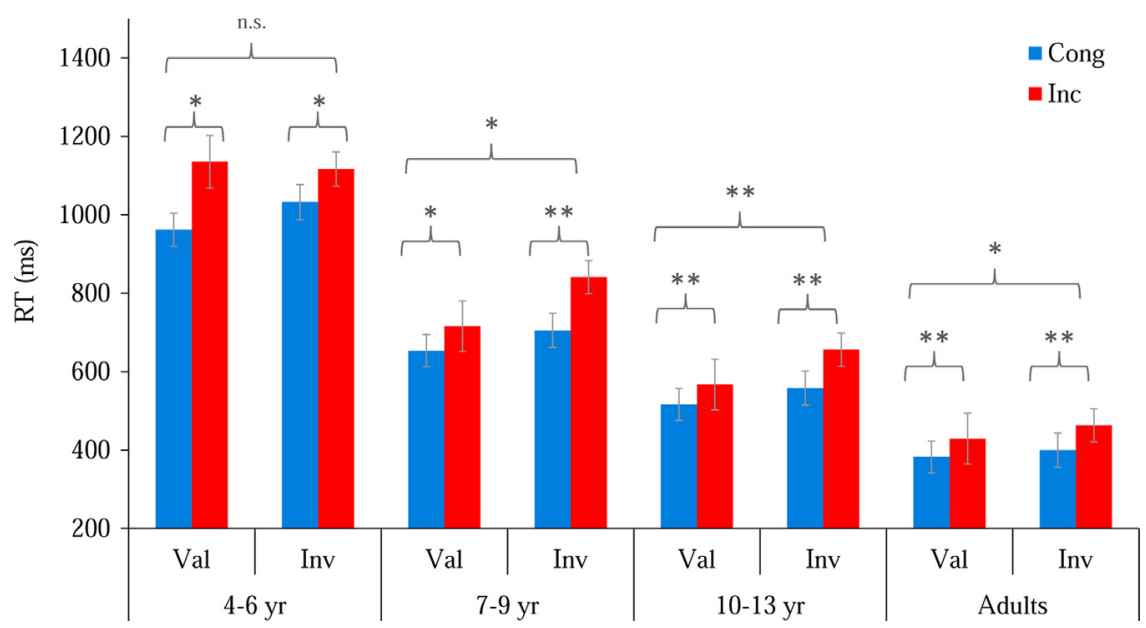

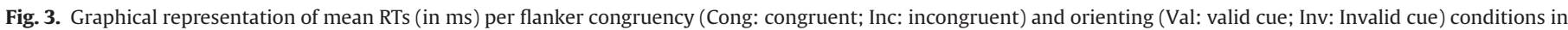
function of age group. 
Table 4

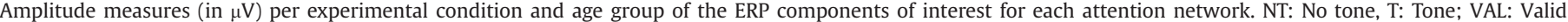

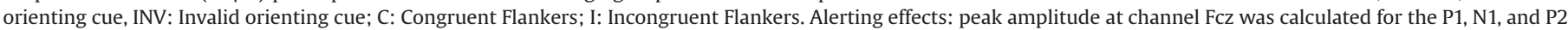

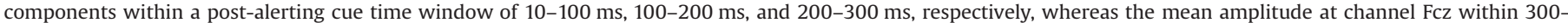

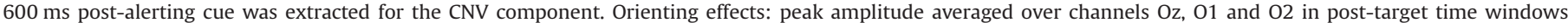

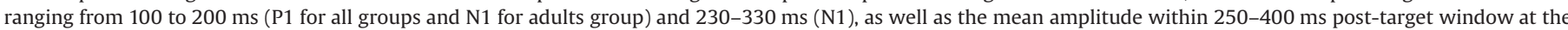

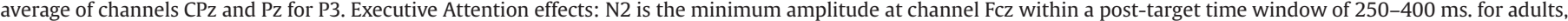
and $400-500 \mathrm{~ms}$. for children; and SP is the mean amplitude at channel Pz, and P6 for 4-6-year-olds, within a post-target time window of 500-800 ms.

\begin{tabular}{|c|c|c|c|c|c|c|c|c|}
\hline \multirow[t]{2}{*}{ ERP components } & \multicolumn{2}{|l|}{ 4-6 yr } & \multicolumn{2}{|l|}{$7-9 \mathrm{yr}$} & \multicolumn{2}{|c|}{$10-13 \mathrm{yr}$} & \multicolumn{2}{|l|}{ Adults } \\
\hline & NT & $\mathbf{T}$ & NT & $\mathbf{T}$ & NT & $\mathbf{T}$ & NT & $\mathbf{T}$ \\
\hline \multicolumn{9}{|l|}{ Alerting effects } \\
\hline P1 & $\begin{array}{l}1.59 \\
(1.99)\end{array}$ & $\begin{array}{l}1.78 \\
(1.83)\end{array}$ & $\begin{array}{l}1.28 \\
(1.61)\end{array}$ & $\begin{array}{l}2.38 \\
(1.31)\end{array}$ & $\begin{array}{l}1.15 \\
(0.87)\end{array}$ & $\begin{array}{l}1.64 \\
(1.59)\end{array}$ & $\begin{array}{l}0.23 \\
(0.43)\end{array}$ & $\begin{array}{l}0.29 \\
(0.47)\end{array}$ \\
\hline N1 & $\begin{array}{l}-2.29 \\
(1.91)\end{array}$ & $\begin{array}{l}-2.63 \\
(2.29)\end{array}$ & $\begin{array}{l}-2.51 \\
(1.31)\end{array}$ & $\begin{array}{l}-2.93 \\
(2.47)\end{array}$ & $\begin{array}{l}-2.14 \\
(1.03)\end{array}$ & $\begin{array}{l}-3.17 \\
(2.53)\end{array}$ & $\begin{array}{l}-0.81 \\
(0.49)\end{array}$ & $\begin{array}{l}-3.22 \\
(1.42)\end{array}$ \\
\hline $\mathbf{P 2}$ & $\begin{array}{l}2.84 \\
(1.50)\end{array}$ & $\begin{array}{l}3.66 \\
(2.62)\end{array}$ & $\begin{array}{l}2.80 \\
(1.28)\end{array}$ & $\begin{array}{l}4.04 \\
(1.87)\end{array}$ & $\begin{array}{l}1.86 \\
(0.71)\end{array}$ & $\begin{array}{l}3.79 \\
(2.10)\end{array}$ & $\begin{array}{l}-0.66 \\
(0.34)\end{array}$ & $\begin{array}{l}1.75 \\
(1.31)\end{array}$ \\
\hline \multirow[t]{2}{*}{ CNV } & $\begin{array}{l}-0.37 \\
(1.22)\end{array}$ & $\begin{array}{l}-1.41 \\
(1.12)\end{array}$ & $\begin{array}{l}-0.43 \\
(0.95)\end{array}$ & $\begin{array}{l}-1.39 \\
(1.47)\end{array}$ & $\begin{array}{l}-0.59 \\
(0.76)\end{array}$ & $\begin{array}{l}-1.35 \\
(1.24)\end{array}$ & $\begin{array}{l}-0.17 \\
(0.36)\end{array}$ & $\begin{array}{c}-1.02 \\
(1.00)\end{array}$ \\
\hline & VAL & INV & VAL & INV & VAL & INV & VAL & INV \\
\hline \multicolumn{9}{|l|}{ Orienting effects } \\
\hline P1 & $\begin{array}{l}12.28 \\
(6.74)\end{array}$ & $\begin{array}{l}8.75 \\
(5.09)\end{array}$ & $\begin{array}{l}23.06 \\
(7.63)\end{array}$ & $\begin{array}{l}16.91 \\
(5.59)\end{array}$ & $\begin{array}{l}15.67 \\
(6.18)\end{array}$ & $\begin{array}{l}12.40 \\
(6.26)\end{array}$ & $\begin{array}{l}4.13 \\
(3.46)\end{array}$ & $\begin{array}{l}4.05 \\
(3.32)\end{array}$ \\
\hline N1 & $\begin{array}{l}1.74 \\
(5.18)\end{array}$ & $\begin{array}{l}0.36 \\
(4.06)\end{array}$ & $\begin{array}{l}7.69 \\
(5.90)\end{array}$ & $\begin{array}{l}8.24 \\
(5.86)\end{array}$ & $\begin{array}{l}5.18 \\
(7.83)\end{array}$ & $\begin{array}{l}7.15 \\
(7.15)\end{array}$ & $\begin{array}{l}-1.40 \\
(2.64)\end{array}$ & $\begin{array}{l}-0.67 \\
(2.19)\end{array}$ \\
\hline \multirow[t]{2}{*}{ P3 } & $\begin{array}{l}1.32 \\
(1.54)\end{array}$ & $\begin{array}{l}1.79 \\
(1.97)\end{array}$ & $\begin{array}{l}2.03 \\
(1.55)\end{array}$ & $\begin{array}{l}2.98 \\
(1.64)\end{array}$ & $\begin{array}{l}1.80 \\
(1.82)\end{array}$ & $\begin{array}{l}2.25 \\
(1.73)\end{array}$ & $\begin{array}{l}0.99 \\
(1.03)\end{array}$ & $\begin{array}{l}1.03 \\
(0.86)\end{array}$ \\
\hline & C & I & C & $\mathbf{I}$ & C & I & C & $\mathbf{I}$ \\
\hline \multicolumn{9}{|c|}{ Executive attention effects } \\
\hline N2 & $\begin{array}{l}-4.24 \\
(1.67)\end{array}$ & $\begin{array}{l}-4.19 \\
(1.67)\end{array}$ & $\begin{array}{l}-6.99 \\
(2.97)\end{array}$ & $\begin{array}{l}-7.05 \\
(3.33)\end{array}$ & $\begin{array}{c}-7.06 \\
(3.99)\end{array}$ & $\begin{array}{c}-7.04 \\
(3.34)\end{array}$ & $\begin{array}{l}-2.15 \\
(1.20)\end{array}$ & $\begin{array}{l}-2.02 \\
(1.09)\end{array}$ \\
\hline SP & $\begin{array}{l}0.60 \\
(1.82)\end{array}$ & $\begin{array}{l}1.13 \\
(1.78)\end{array}$ & $\begin{array}{l}-2.13 \\
(1.99)\end{array}$ & $\begin{array}{l}3.30 \\
(2.40)\end{array}$ & $\begin{array}{l}2.47 \\
(2.23)\end{array}$ & $\begin{array}{l}2.79 \\
(2.36)\end{array}$ & $\begin{array}{l}1.17 \\
(1.04)\end{array}$ & $\begin{array}{l}1.41 \\
(1.16)\end{array}$ \\
\hline
\end{tabular}

\subsubsection{Alerting cue-locked ERPS}

3.2.1.1. Alerting network. ERPs per alerting condition over mid-frontal leads for each age group are presented in Fig. 4. Topographic maps at the time of amplitude peaks corresponding to P1, N1, P2 and CNV components show a clear mid-frontal distribution of those components. Therefore, peak amplitude values of the corresponding polarity were extracted for channel Fcz at the following time windows: $10-100 \mathrm{~ms}$ for P1, $100-200 \mathrm{~ms}$ for $\mathrm{N} 1,200-300$ for P2 and $300-600 \mathrm{~ms}$ for the $\mathrm{CNV}$, and sets of 2 (Alerting Cue: tone vs. notone) $\times 4$ (Age Groups) ANOVAs were performed with those values. The Age Group factor was significant for the P1 $(F(3,55)=4.32$; $\left.p<0.01, \eta_{\mathrm{p}}^{2}=0.25\right)$ and P2 $\left(F(3,55)=9.57 ; p<0.001, \eta_{\mathrm{p}}^{2}=0.34\right)$. The effect of Alerting Cue was significant for all the components taken into account: P1 $\left(F(1,55)=4.74 ; p<0.05, \eta_{\mathrm{p}}^{2}=0.08\right)$, N1 $(F(1,55)=$ $\left.16.30 ; p<0.001, \eta_{\mathrm{p}}^{2}=0.23\right), \mathrm{P} 2\left(F(1,55)=23.83 ; p<0.001, \eta_{\mathrm{p}}^{2}=0.30\right)$, and $\operatorname{CNV}\left(\mathrm{F}(1,55)=25.50 ; p<0.001, \eta_{\mathrm{p}}^{2}=0.32\right)$. Finally, the Age Group $\times$ Alerting Cue interaction was significant only for the N1 $\left(F(3,55)=3.39 ; p<0.05, \eta_{\mathrm{p}}^{2}=0.16\right)$. Further analyses of the interaction revealed that only adults showed a significant effect of Alerting Cue on the $\mathrm{N} 1(\mathrm{~F}(1,55)=21.82 ; p<0.01)$. This effect was marginal in 10 13 years-olds $(F(1,55)=3.96 ; p=0.05)$.

\subsubsection{Target-locked ERPS}

3.2.2.1. Orienting network. Fig. 5 presents ERP for valid- and invalid-orienting cue trials (Orienting Network), and Fig. 6 shows ERP for congruent and incongruent conditions (Executive Attention Network). ERPs per orienting condition for each age group, both at parietal and occipital sites, are presented in Fig. 5. Peak amplitudes were extracted for each participant at time windows ranging from 100 to $200 \mathrm{~ms}, 100$ to 200 (adults) or 230 to 330 (children), and 300 to $400 \mathrm{~ms}$, respectively for the P1, N1 and P3 ERP components at the average of channels $\mathrm{Oz}, \mathrm{O} 1$ and $\mathrm{O} 2$ (for $\mathrm{P} 1$ and $\mathrm{N} 1$ ) and $\mathrm{CPz}$ and $\mathrm{Pz}$ (for the $\mathrm{P3}$ component). These data were entered in separated ANOVAs including Age Group (4-6, 7-9, 10-13 yearsold, and adults) and Orienting Cue (valid- vs. invalid-cue) conditions as factors. The effect of Age Group was significant for each component $\left(F(3,55)=24.46 ; p<0.001, \eta_{\mathrm{p}}^{2}=0.57\right.$ for the P1, $F$ $(3,55)=10.10 ; p<0.001, \eta_{\mathrm{p}}^{2}=0.35$ for the $\mathrm{N} 1$, and $F(3,55)=9.86$; $p<0.05, \eta_{\mathrm{p}}^{2}=0.14$ for the P3). The effect of Orienting Cue was significant for the P1 $\left(F(1,55)=28.18 ; p<0.001, \eta_{\mathrm{p}}^{2}=0.34\right)$ and P3 $(F$ $\left.(1,55)=9.87 ; p<0.01, \eta_{\mathrm{p}}^{2}=0.15\right)$, and not significant for the N1 $(F<1)$. Also, the Age Group $\times$ Orienting Cue interaction was significant for the P1 $\left(F(3,55)=4.17 ; \quad p<0.01, \quad \eta_{\mathrm{p}}^{2}=0.18\right)$ Subsequent analyses of this interaction revealed that the effect of Orienting Cue on the amplitude of the P1 peak was significant for all children groups $(F(1,55)=7.85 ; \quad p<0.01, \quad F(1,55)=25.58$; $p<0.001$, and $F(1,55)=7.22 ; p<0.01$, respectively for $4-6,9-7$ and $10-13$ years-olds) but did not reach significance in the group of adults $(F<1)$.

3.2.2.2. Executive network. Regarding the modulation of ERP by the congruency of flankers, peak amplitude of Fcz for adults within a 250-400 ms and Fcz for children within 400-500 ms after target (when negative deflection was observed), as well as mean amplitude of $\mathrm{Pz}$ within a $500-800 \mathrm{~ms}$ post-target time window were extracted for each participant (see Fig. 6). These data were included in separated ANOVAs with Age Group (4-6, 7-9, 10-13 years-old, and adults) and Flanker Congruency (congruent vs. incongruent) conditions as factors. The effect of Age Group was significant for the $\mathrm{N} 2$ component $(F(3,55)=15.27 ; p<0.001$, $\left.\eta_{\mathrm{p}}^{2}=0.45\right)$ but did not reach significance for the SP $(F(3,55)=$ 1.95; $p=0.13, \eta_{\mathrm{p}}^{2}=0.09$ ). The effect of Flanker Congruency was 


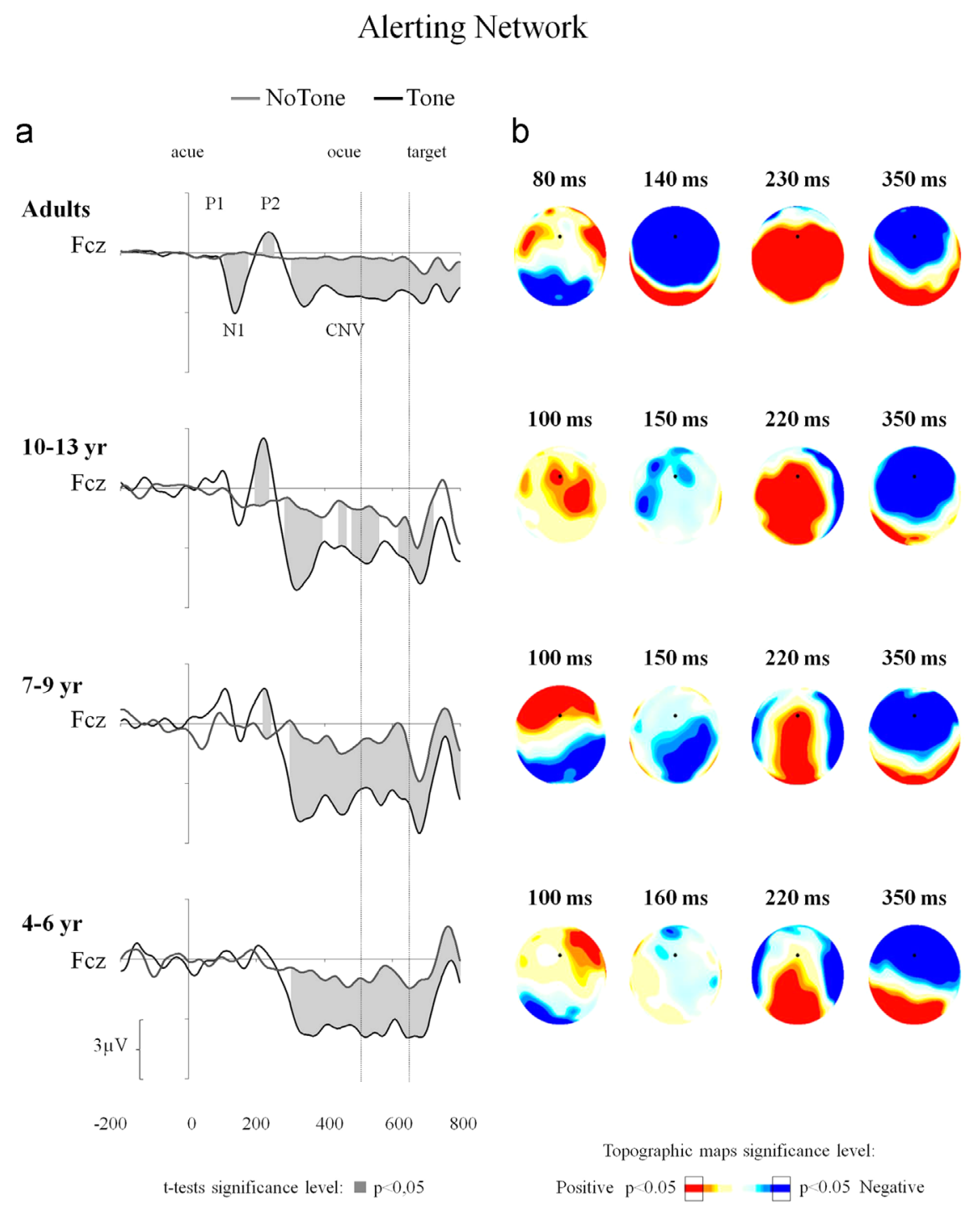

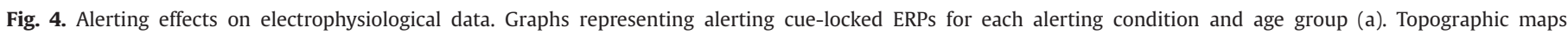

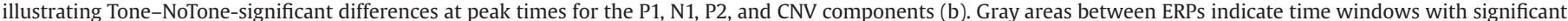
$(p<0.05)$ amplitude differences between conditions computed by two-tailed $t$-tests. acue: alerting cue; ocue: orienting cue. Note that positivity is plotted upwards.

significant only for the SP $\left(F(1,55)=16.68 ; p<0.001, \eta_{\mathrm{p}}^{2}=0.23\right)$. Finally, the Age Group $\times$ Flanker Congruency interaction was not significant in any of the components $(F<1$ for both). We found a lack of flanker interference modulation of the $\mathrm{N} 2$ in children. However, amplitude modulation by flanker congruency was observed after $400 \mathrm{~ms}$ post-target, as shown by $t$-tests (see Fig. 6).

3.2.2.3. Interactions between attention networks. Lastly, in order to examine modulation of alerting and orienting conditions on the executive attention effect, ERPs corresponding to congruent and incongruent conditions were averaged separately in function of the conditions of the other two networks. Splitting the data in this way left insufficient artifact-free segments to average across subjects in the children groups, therefore these analyses were only performed with data from the adults' sample, ERPs that resulted from these analyses are presented in Fig. 7. As before, the shadowed areas between the ERPs corresponding to the congruent and incongruent conditions show time windows with significant amplitude differences between the two conditions as measured by paired-samples $t$-tests.
To analyze the interaction between alerting and executive attention, two separate 2 (Alerting Cue: tone vs. no-tone) $\times$ 2 (Flanker Congruency: congruent vs. incongruent) ANOVAs were performed with amplitude of the N2 (minimum amplitude within a time-window of $250-400 \mathrm{~ms}$ post-target at Fcz ) and SP (mean amplitude within a time-window of $500-800 \mathrm{~ms}$ post-target at $\mathrm{Pz}$ ) components. For the N2, results showed a main effect of Alerting $(F$ $\left.(1,14)=10.56 ; p=<0.05, \eta_{\mathrm{p}}^{2}=0.42\right)$ but no effect of Flanker Congruency or Alerting $\times$ Flanker Congruency $(F<1)$. For SP, a main effect of Flanker Congruency $\left(F(1,14)=4.86 ; p=<0.05, \eta_{\mathrm{p}}^{2}=0.26\right)$ emerged, but no effect of Alerting or interaction between the two factors was found $(F<1)$. To analyze the Orienting $\times$ Executive networks interaction, two separate 2 (Orienting Cue: valid vs. invalid) $\times 2$ (Flanker Congruency: congruent vs. incongruent) ANOVAs were performed, one using the peak amplitude of the N2 at Fcz within a time window of $250-400 \mathrm{~ms}$ post-target, and a second one using the mean amplitude at Pz within a time window of 500$800 \mathrm{~ms}$ post-target. For the first ANOVA neither main effects nor the interaction between the factors were significant. In the second ANOVA, only the main effect of Flanker Congruency $(F(1,14)=11.60$; $p=<0.01, \eta_{\mathrm{p}}^{2}=0.45$ ) was significant. 
Orienting Network

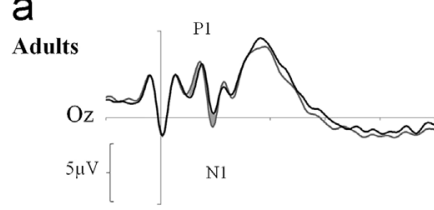

$10-13 \mathrm{yr}$
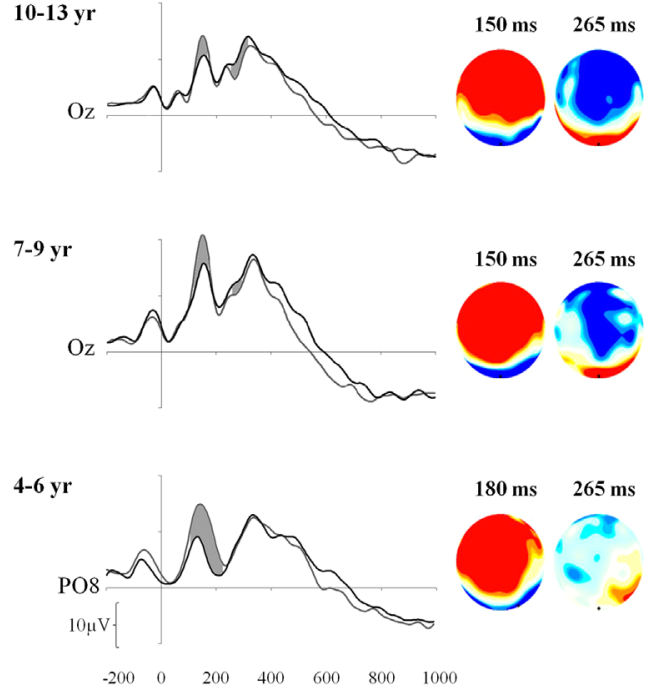

t-tests significance level: $=\mathrm{p}<0,05$
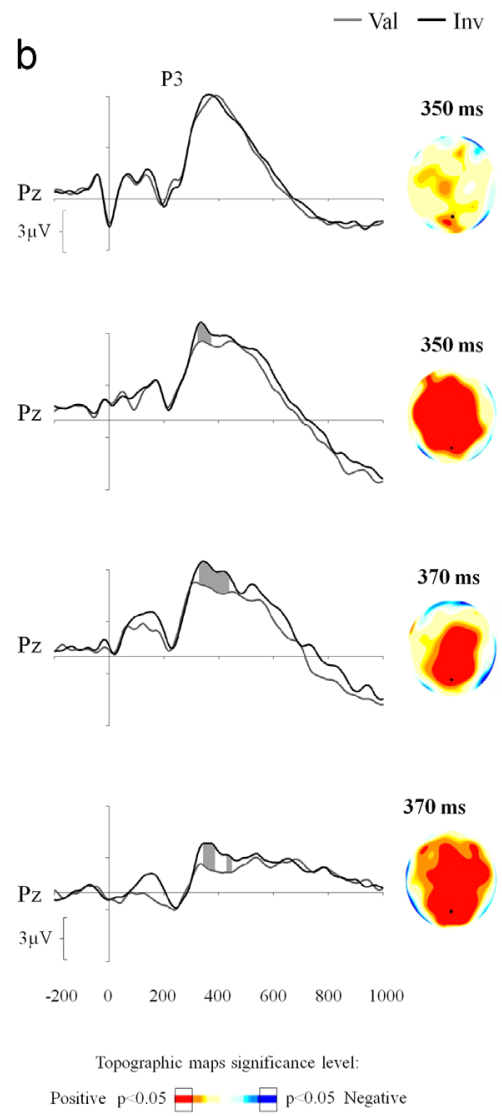

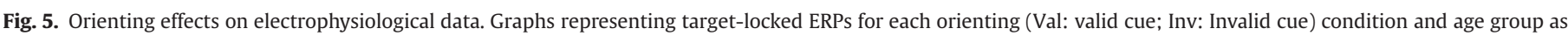

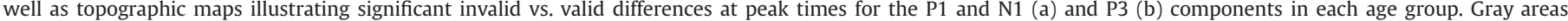
between ERPs indicate time windows with significant $(p<0.05)$ amplitude differences between conditions computed by two-tailed $t$-tests.

\section{Discussion}

This study examined age-related differences in attentional networks efficiency at behavioral and electrophysiological levels with the goal of understanding cognitive and brain mechanisms underlying the development of attention functions. As expected, age-related changes in the efficiency of attention networks were observed, which, in the age range studied, were more pronounced for the orienting and executive attention networks. We did not find a significant age effect on alerting scores, but there was a trend to larger alerting effects for younger children compared to older children and adults. Orienting scores showed a different developmental trajectory, with no significant differences among the children groups, but significant differences between 7-9 and 10-13 children and adults. Finally, executive attention scores showed a more protracted reduction over the age range studied, indicating a progressive gain in efficiency of conflict processing with age. Overall, the developmental trajectories obtained in this study replicate what was observed before with a similar version of the task (Pozuelos et al., under review; Experiment 1) and in other studies using different procedures to measure the same functions (Waszak et al., 2010). Additionally, alerting and orienting conditions modulated efficiency of executive attention in ways that were expected according to previous research (Callejas et al., 2005; Pozuelos et al., under review). Overall, interference suppression was less efficient after presentation of a warning auditory tone, and also following invalid orienting cues. In the current study, we found that these interactions were qualified by the age of participants, a second-order interaction that was mostly derived from the youngest group of children. The modulatory effect of alerting over executive attention was stronger for the youngest group, who only showed a significant flanker interference effect when a warning tone preceded the target (see Fig. 2). Also, the youngest children, contrary to the rest of the groups, showed equivalent interference effects following valid and invalid orienting cues (see Fig. 3). In the developmental study conducted by Pozuelos et al. (under review) no second-order interactions with age were observed, which could be due to the fact that the youngest group included in that study was 6 and a half years on average, whereas in this study the average age of the youngest group was 5 years. Below we discuss these developmental patterns in relation to ERP data obtained in this and other studies.

\subsection{Alerting network}

Previous studies have shown that young children (5-yearolds) need more time than older children (8-year-olds) and adults to get full benefit from a warning cue (Berger, Jones, Rothbart, \& Posner, 2000), and they also seem to be less able to sustain the optimal level of alertness over time (Morrison, 1982). The fact that alertness is subject to more fluctuations in younger children can in part explain age differences in processing speed because alertness is thought to speed the processing of subsequent events. Using the ANT, Rueda, Fan et al. (2004) found no differences in alerting between 10-year-olds and adults with the child ANT, but the same group of children showed a relatively poor ability compared to adults maintaining the alert state in the absence of a warning signal when using the adult ANT. Separation of the alerting and orienting events, and inclusion of trials with invalid orienting cues, is likely to have made the current 


\section{Executive Network}

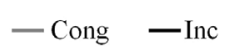

a

Adults

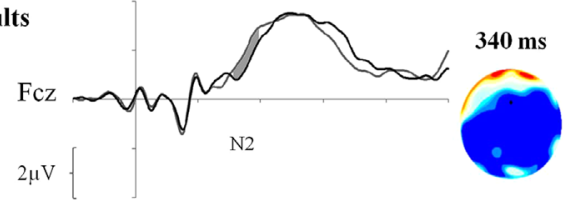

$10-13$ yr

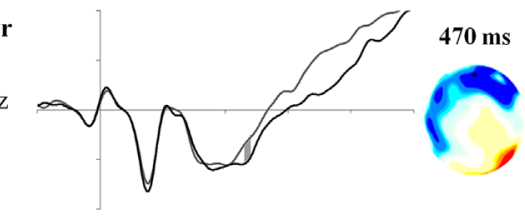

$7-9 \mathrm{yr}$

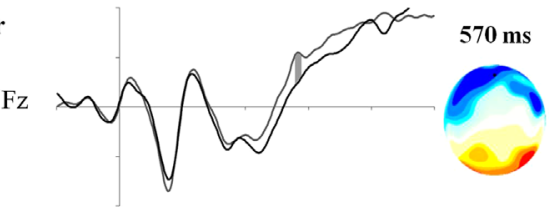

4-6 yr

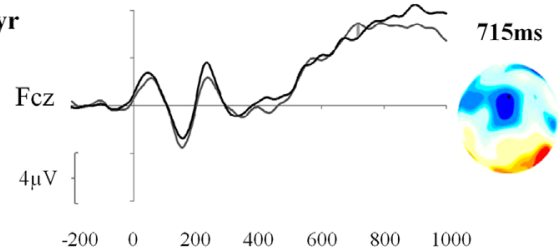

b

$\mathrm{Pz}$

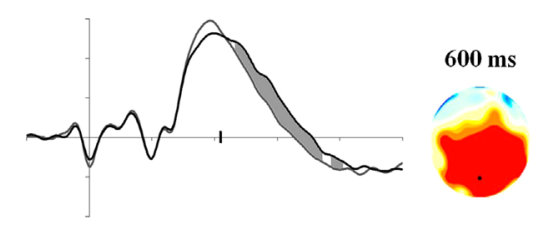

$\mathrm{Pz}$

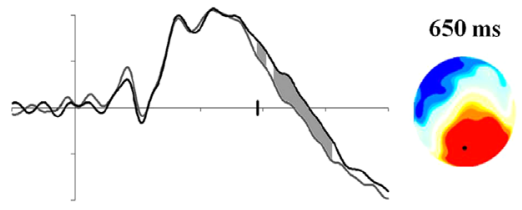

$\mathrm{Pz}$

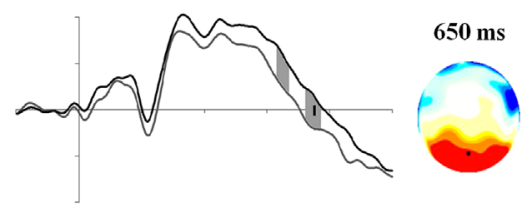

P6

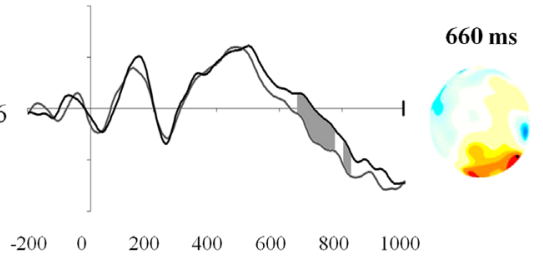

Topographic maps significance level:

Positive $\mathrm{p}<0.05 \boxminus \quad \square \mathrm{p}<0.05$ Negative

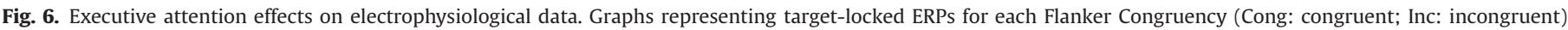

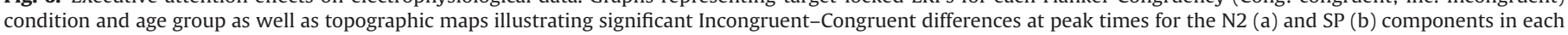

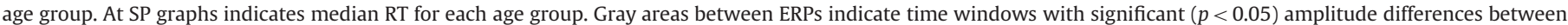
conditions computed by two-tailed $t$-tests.

version of the child ANT some more challenging than the one used by Rueda and colleagues. Behavioral results in our study showed a lack of age effect for the alerting score. However, ERP analyses revealed a poorer processing of the alerting signal by children below age 9 compared to older children and adults (see Fig. 4). While adults showed the usual electrophysiological pattern associated with the early processing of an auditory cue, the AEP complex (Ponton, Eggermont, Kwong, \& Don, 2000) followed by the $\mathrm{CNV}$, children data revealed a number of differences compared to adults. First, while the presence of the alerting tone modulated the amplitude of the P1 and P2 peaks in 7-9- and 10-13-year-old children, 4-6-year-olds did not show any differences on amplitude between tone and no-tone conditions until about $300 \mathrm{~ms}$ after presentation of the tone. Evidence in the literature indicates that central auditory pathways have a maturational time course that extends into adolescence (Ponton et al., 2000; Sharma, Kraus, J. McGee, \& Nicol, 1997). The AEP complex has been associated with sensory encoding and integration of auditory stimuli (Hegerl \& Juckel, 1993). Developmental studies have found an early maturing P1 and P2 in response to auditory cues, but a later emergence of the N1, which appears around 10 years of age (Čeponien et al., 2002; Ponton, Don, Eggermont, Waring, \& Masuda, 1996; Ponton et al., 2000). Our data are in line with these findings because only adults show a clear N1 peak following the alerting tone. Also, both the size and latency of the P1 decrease with age, whereas the P2 is present from mid childhood, showing a latency and topography similar to that of the adults. Regardless of the differences found in the early processing of the alerting cue, all age groups presented a CNV starting at approximately $300 \mathrm{~ms}$ after the presentation of the tone. Bender et al. (2005) have reported that children from 6 to 12 years of age do not show the late component of the CNV associated to motor pre-activation. However, the relatively short foreperiod $(650 \mathrm{~ms})$ used in our task does not allow drawing further conclusions about possible developmental differences on early and late components of the CNV.

Other studies have also found differences in brain activity during development in response to targets that are preceded by warning cues. In a fMRI study using a modified version of the adult ANT, Konrad et al. (2005) found that adults exhibit the classic fronto-parietal activation in the right ventral prefrontal cortex and the left superior parietal gyrus when processing targets preceded by alerting signals. However, 10-12-year-old children did not show activation in those areas. Instead, they showed increased activity in the right middle occipital cortex and right superior temporal gyrus. These remarkable differences were found in spite of a lack of differences in alerting scores between children and adults. Altogether, data suggest that the alerting network shows a poor early processing of warning signals in early and middle childhood. Further maturational processes of this network that are not observable at the behavioral level may still occur during late childhood. 
No Tone - Cong - Inc Tone

a
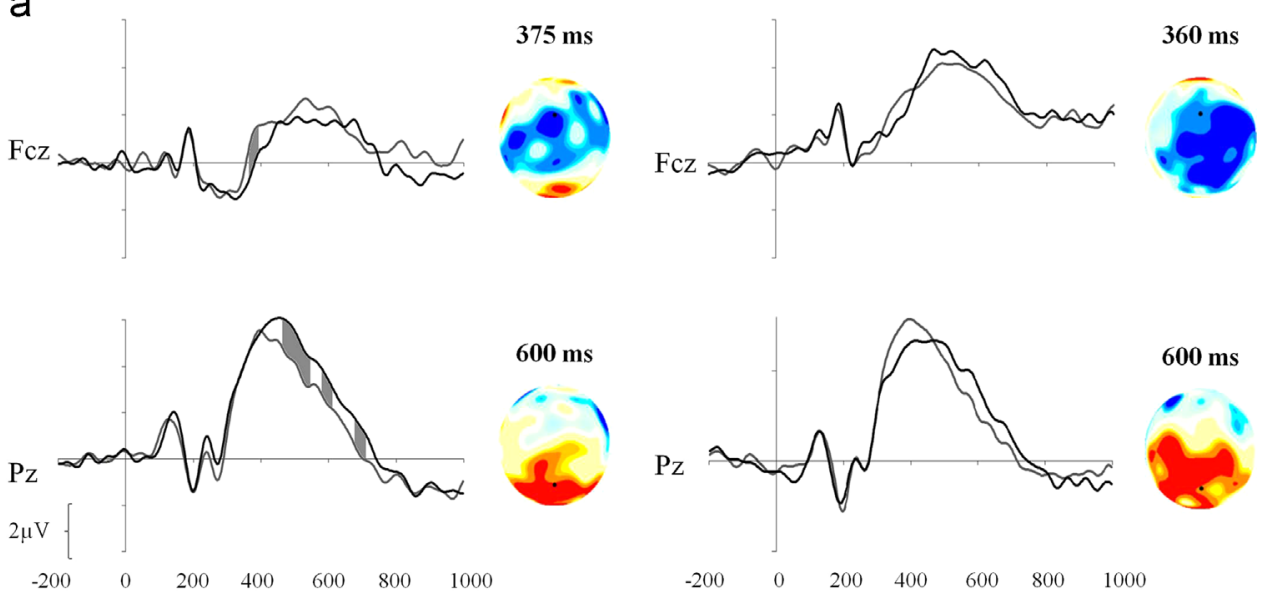

b Valid

Invalid
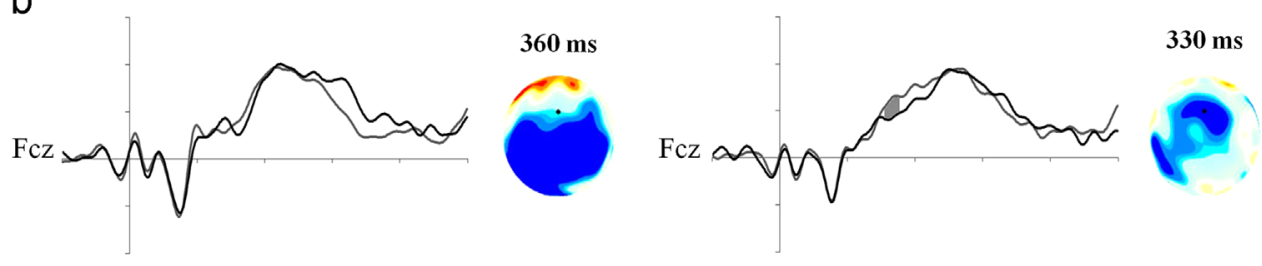

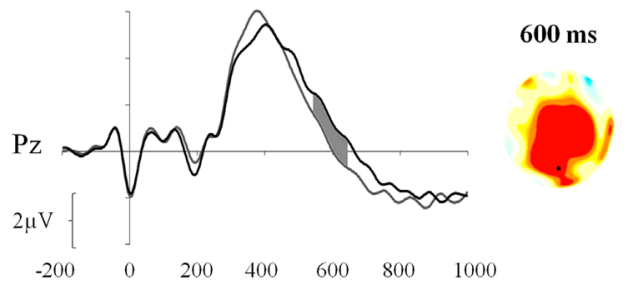

t-tests significance level: $\mathbf{p}<0,05$

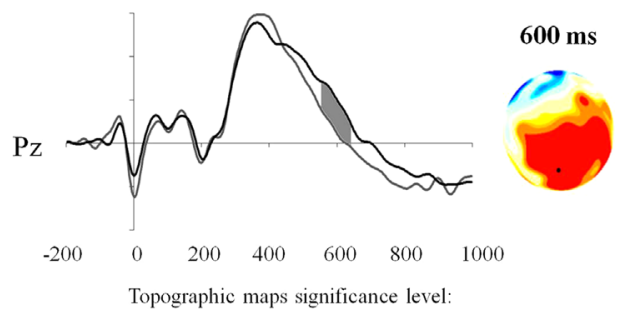

Positive $\mathrm{p} 0.05 \boxminus \quad \square \mathrm{p} 0.05$ Negative

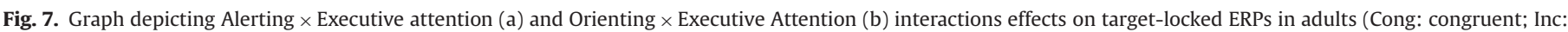

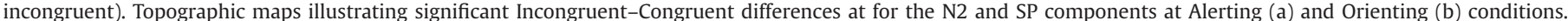
Gray areas between ERPs indicate time windows with significant $(p<0.05)$ amplitude differences between conditions computed by two-tailed $t$-tests.

\subsection{Orienting network}

Efficiency scores for the orienting network provided in this study, which were obtained subtracting valid- from invalid-cue trials, mostly grasp processes related to disengagement and reallocation of attention (Posner \& Cohen, 1984). When development of orienting is examined using only valid cues, no age differences are observed beyond age 5 and adults (Rueda, Fan et al., 2004; Wainwright \& Bryson, 2002). However, our data reveal a developmental trajectory of this function that extends to late childhood, which is most likely due to maturation of brain structures involved in disengaging and switching attention from one location to another.

A number of posterior ERP components (i.e., P1, N1, and P3) have been long associated with visual processing (Mangun, 1995; Mangun \& Hillyard, 1987). Of those, the P1 and N1 components are related to early sensorial processing. These potentials are typically larger in amplitude after valid than invalid cues when short cue-target intervals (i.e., below $500 \mathrm{~ms}$ ) are used (see Chica \& Lupiañez, 2009 for a reversed pattern when cue-target intervals that promote inhibition of return are used). The larger amplitude on valid-cue trials is associated with attention-related sensory gain at an early stage of processing of the target (Luck \& Hillyard, 1995; Mangun, 1995). Studies of spatial attention have shown that the N1 is enhanced by valid orienting cues on choice RT tasks but not when simple RT tasks are used, while the P1 amplitude is modulated by attention cues independently of the type of task (Luck \& Hillyard, 1995; Mangun \& Hillyard, 1991; Ritter, Simson, Vaughan Jr., \& Macht, 1982). This suggests that the P1 is a rather exogenous ERP index of early visual processing, while the N1 may reflect a more complex processing phase, involving discrimination of information conveyed by different cortical processing streams (Vogel \& Luck, 2000). In our study, orienting cues produced a consistent early modulation of the P1 amplitude in all age groups (see Fig. 5). This indicates that children used the cues to successfully orient attention, as is also suggested by faster RT for valid-cue trials. Additionally, 4-6-year olds did not show modulation of the N1 amplitude. Modulation of this component was expected given that the task used in our study involved discriminating the direction of the central fish. The fact that children below age 7 years do not show modulation of the $\mathrm{N} 1$ indicates that attention has greater impact at earlier stages of visual processing in young children, whereas it continues to have an impact on subsequent stages of visual processing in older children and adults. 
On the other hand, the P3 shows a rather opposite developmental pattern. This potential is also modulated by validity of the cue, showing larger amplitude at invalid compared to valid-cue trials (Bledowski, Prvulovic, Goebel, Zanella, \& Linden, 2004; Gómez et al., 2008), and thus has been related to processes of disengagement and reorienting of attention. In our study, modulation of the P3 by the validity of the cue was larger for the youngest group of children. This result is consistent with data from previous studies (Flores et al., 2010), and suggests that young children engage fronto-parietal structures to a greater extent than older children and adults in order to disengage and move attention from the location of the cue to the location of the target in invalid-cue trials.

In sum, our data suggest that children under 7 years of age are not yet completely efficient when it comes to use valid orienting cues to facilitate the processing of a target. Moreover, when the target is presented at a different location from that of the orienting cue and attention has to be reallocated, even the older children in our study show larger costs than that shown by adults.

\subsection{Executive attention network}

In line with previous results using similar tasks (Fjell et al., 2012; Ridderinkhof \& van der Molen, 1995), we found a linear reduction of conflict scores with age. With a version of the child ANT that only includes valid orienting cues, the executive attention network was shown to reach adults' levels of efficiency after about age 7 years (Rueda, Fan et al., 2004). However, data from the current study suggest a developmental trajectory for this network that extends to late childhood. The inclusion of invalid orienting cues in the current version of the task caused increased interference from flankers, as indicated by the significant Orienting $\times$ Executive attention interaction with both $\mathrm{RT}$ and commission errors (see Table 1 and Fig. 3), which likely led to a more protracted development of conflict resolution than was observed with the original child ANT. This interpretation is supported by data from a recent developmental study in which a progressive development of executive attention from 6 to 12 years of age was found using the same version of the child ANT (Pozuelos et al., under review, Experiment 1).

As expected, electrophysiological recordings revealed a modulation of the N2 amplitude by the congruency of flankers in adults (see Fig. 6). As revealed by $t$-tests, the modulation is observed in mid-frontal channels at about $350 \mathrm{~ms}$ post-target. This effect was not observed in children, rather we observed a delayed and more anterior effect of flanker congruency over central anterior channels. Such effect was sustained for a longer period of time in children compared to adults. Data in the literature about developmental changes in conflict-related modulations of the $\mathrm{N} 2$ effect greatly depend on the task being used. Several studies using Go-NoGo tasks have reported larger conflict effects in N2 amplitude by young children compared to older children and adults (Hämmerer et al., 2010; Lamm et al., 2006). This result suggests that the larger the effect on the amplitude of the N2 the poorer the executive control efficiency. As a matter of fact, Lamm et al. (2006) reported an age-related decrease in N2 amplitude between 7 and 16 years of age. However, using a flanker task with arrows, Ladouceur et al. (2007) found that only late adolescents (i.e., older than 14 years) and adults showed larger N2 amplitude in trials with incongruent flankers, while an early adolescents group also included in the study did not show the effect. Our results are consistent with data from this study as well as with those reported by Rueda, Posner et al. (2004) where young children did not show N2 amplitude modulation by flanker congruency but a sustained frontal effect after $500 \mathrm{~ms}$ post-target.
On the contrary, we found that conflict-related modulation of the SP amplitude was observed in all age groups. It is noteworthy that this potential was observed for the most part after the response in 10-13-year-olds and adults, whereas it was shown around the time of the response (7-10-year olds) or before it (4-7year olds) for the younger groups. This indicates that the SP potential is somewhat independent of the response and could either be directly involved on conflict resolution or could signal a post-response neural activation for adjustments and sustained control of goal-directed behavior (Coderre et al., 2011). Imaging studies have suggested that executive control is related to the action of two differentiated neural networks, one involved in trialto-trial response adaptation (adaptive control), and another mostly related to stable control (set maintenance) along the duration of the task (Dosenbach, Fair, Cohen, Schlaggar, \& Petersen, 2008). The two systems appear to be functionally segregated in adults but not completely so in late childhood (Fair, Dosenbach, Church, Cohen, Brahmbhatt, \& Miezin, 2007). It has been previously suggested that, because of children generally slower capacity for processing information, they show conflictrelated effects in later ERP components compared to adults (Rueda, Posner et al., 2004). This could explain why children did not show a conflict-related modulation of the N2 component. Instead children showed delayed effects in frontally distributed leads as well as modulation of the SP potential. Determining whether the two ERP components represent waves of activation of the same or different underlying conflict processing systems, and/or whether they reflect equivalent action-control mechanisms, requires further research.

\subsection{Networks interactions}

Despite their anatomical separation, there is evidence indicating that the attention networks are not functionally independent (Callejas et al., 2005; Fan et al., 2009). It has been previously shown that both alerting and orienting conditions modulate efficiency of the executive attention network (Callejas, Lupiáñez, \& Tudela, 2004; Weinbach \& Henik, 2012). These modulatory effects were replicated in the current study. Further, in our study, we were able to test whether these patterns of interactions between attention networks change with age along childhood.

Our data revealed that efficiency of executive attention was harmed when a warning tone was presented prior to the appearance of the target. This effect has been interpreted before as indicative of an inhibitory relation between the alerting and executive networks. The idea is that warning signals promote fast and automatic responses over more controlled forms of action (Posner, 1994). Our results show that alerting signals reduced RT mostly in the congruent condition, leading to lager flanker effects in that condition compared to when no alerting tone was presented (see Fig. 2). This effect was present in all age groups, although it was somewhat stronger for the youngest group of children. This result agrees mostly with the account of alertness promoting fast and automatic responses. However, it has been also proposed that alerting influences the allocation of attention by prioritizing the processing of spatial information, thus leading to enhanced processing of distracting stimulation (Weinbach \& Henik, 2012). According to this hypothesis, larger interference effects are due to the necessity for greater implication of the executive system in order to suppress the influence of distracting stimulation with higher alertness.

The second modulatory effect over efficiency of executive attention was that of orienting cues. The significant Orienting $\times$ Executive Attention $\times$ Age in our study indicated that the interaction between orienting and executive attention differed among age groups. As can be seen in Fig. 3, for all age groups 
except the youngest children, executive scores were higher (i.e., poorer efficiency) when invalid orienting cues were presented prior to the appearance of the target. After invalid cues, reallocation of attention is needed, a process that is thought to engage a fronto-parietal network (Corbetta \& Shulman, 2002) that may partially overlap with structures involved in suppressing irrelevant stimulation (Fan et al., 2007; Fan, McCandliss, Fossella, Flombaum, \& Posner, 2005). It has been suggested that during the interaction between orienting and executive attention a competition for limited attentional resources from shared brain structures takes place (Fan et al., 2009). The lack of interaction in the youngest children, may be related to the fact that conflict processing was difficult for children of this age regardless of the facilitation offered by valid orienting cues. In fact, valid cues only reduced RT in the easiest (i.e., congruent) flanker condition in this age group.

These patterns of interactions between attention networks were not observed with electrophysiological recordings. The $t$-test results indicated that warning auditory cues might affect the brain potentials associated with conflict processing in adults. Specifically, presence of the tone appeared to cause larger conflict effect on the SP component, whereas did not seem to affect the size of the conflict effect on the N2 (see Fig. 7a). As argued before, greater SP amplitude for displays with incongruent distractors is likely related to stronger activation of the fronto-parietal network involved in sustained attention control (Dosenbach et al., 2008), which is even stronger after warning cues are presented, reflecting the greater effort required to deal with conflict in higher alerting states. ERP results are less clarifying of the neural mechanisms underlying the Orienting $\times$ Executive attention interaction. As can be observed in Fig. 7b, the size of the conflict-related amplitude effect on both the N2 and SP components is similar under valid and invalid orienting conditions. In general, inconsistencies between brain and behavioral measures of interactions between attention networks may be due to the smaller number of trials available to study interactions with brain potentials. Further investigation is needed in order to cast light into the neural mechanisms underlying the pattern of interactions between attention network observed at the behavioral level.

\subsection{Limitations of the study}

One of the main limitations of the current study relates to the unfeasibility to examine interactions between attention networks on electrophysiological recordings in the children sample. Changes introduced to the task design led to a larger number of conditions in this version ( 2 Alerting $\times 3$ Orienting $\times 2$ Congruency $=12$ cells) compared to the original version (4 Alerting/Orienting Cues $\times$ 2 Congruency $=8$ cells) of the ANT. A larger number of conditions inevitably lead to longer tasks if the number of observations per cell is to remain constant. However, task length can be an issue when running developmental studies because of young children's shorter attention/motivation span compared to adults. In order to minimize the influence of such factors in our study we chose to keep the task as short as possible for the children groups. This derived in an insufficient number of observations to examine networks interactions when trials with incorrect responses and EEG artifacts were discarded. In future studies, it might be useful to examine interactions between networks in separate tasks, thus reducing the number of cells in the design, in order to acquire sufficient data points with reasonable task lengths.

\subsection{Summary and conclusions}

The main goal of the current study was to examine the electrophysiological patterns of activations underlying the development of attention functions of alerting, orienting and executive control during childhood. For doing so, a modified version of the child ANT was used. In this new version of the task, separate events in each trial were introduced to manipulate alertness, orienting and conflict, as in Callejas et al. (2005) and Pozuelos et al. (under review). In consonance with previous data in the literature, behavioral results indicate that the three attentional functions follow different developmental trajectories during childhood (see Rueda, 2013 for a review). While the alerting function appears adult-like by age 10 , both orienting and executive attention showed a more protracted developmental curve. In the current version of the ANT, both valid and invalid orienting cues were used. Invalid cues grasp mostly aspects of attentional disengagement and re-orienting, which lengthen the developmental trajectory of orienting compared to when only valid cues are used (Rueda, Fan et al., 2004). Finally, executive attention exhibited a linear increase in efficiency with age that might go beyond the age range of children included in our study (Fjell et al., 2012; Waszak, 2010).

EEG recordings during performance of the task evinced differences between children and adults related to the activation of all three attention networks. Overall, age-related changes were mostly observed on early ERP components, suggesting that, compared to adults, children exhibit a poorer fast processing of conditions varying in attentional requirements. Young children appear to have poorer early processing of warning cues compared to 10 -13-year-olds and adults, judging from the immature AEP complex elicited by warning auditory tones in children below 10 years of age. Also, the youngest groups exhibited a poorer processing of orienting cues in early (N1) as well as late (P3) ERP components, indicating that they are not yet able to obtain a full facilitatory effect from valid cues, and must activate the orienting network to a greater extent in order to shift attention when invalid cues are presented. Finally, the lack of conflict-related modulation of the N2 component in all children groups suggests that the executive attention network is not yet fully mature at 13 years of age.

Results from this study also inform about patterns of interactions among attention networks in adulthood and over development. Both alerting and orienting conditions influence the effectiveness of conflict processing by the executive attention network. Higher alerting states lead to poorer conflict processing in all age groups, an effect that, at least in adults, appear to be associated with less efficient recruitment of the executive attention network following a warning signal. On the other hand, as children gain in executive attention efficiency after the preschool period, resources devoted to reallocating attention when invalid orienting cues are provided also reduce the effectiveness of executive control.

\section{Acknowledgments}

Research presented in this article was supported by a grant from the Spanish Ministry of Science and Innovation (Ref. PSI2011.27746) to M.R.R. and a pre-doctoral fellowship from the Spanish Agency for International Cooperation (AECID) awarded to the fist author. This paper is part of the doctoral dissertation of the first author.

\section{References}

Band, G. P. H., van der Molen, M. W., Overtoom, C. C. E., \& Verbaten, M. N. (2000) The ability to activate and inhibit speeded responses: Separate developmental trends. Journal of Experimental Child Psychology, 75, 263-290, http://dx.doi.org/ 10.1006/jecp.1999.2538.

Bekker, E. M., Kenemans, J. L., \& Verbaten, M. N. (2004). Electrophysiological correlates of attention, inhibition, sensitivity, and bias in a continuous 
performance task. Clinical Neurophysiology, 115, 2001-2013, http://dx.doi.org/ 10.1016/j.clinph.2004.04.008.

Bender, S., Weisbrod, M., Bornfleth, H., Resch, F., \& Oelkers-Ax, R. (2005). How do children prepare to react? Imaging maturation of motor preparation and stimulus anticipation by late contingent negative variation. NeuroImage, 27 (4), 737-752, http://dx.doi.org/10.1016/j.neuroimage.2005.05.020.

Berger, A., Jones, L., Rothbart, M. K., \& Posner, M. I. (2000). Computerized games to study the development of attention in childhood. Behavior Research Methods, Instruments, and Computers, 32(2), 297-303.

Berger, A., \& Posner, M. I. (2000). Pathologies of brain attentional networks Neuroscience \& Biobehavioral Reviews, 24(1), 3-5, http://dx.doi.org/10.1016/ S0149-7634(99)00046-9.

Bledowski, C., Prvulovic, D., Goebel, R., Zanella, F. E., \& Linden, D. E. J. (2004). Attentional systems in target and distractor processing: A combined ERP and fMRI study. Neuroimage, 22, 530-540, http://dx.doi.org/10.1016/j.neuroimage. 2003.12.034.

Brunia, C. H. M., \& Damen, E. J. P. (1988). Distribution of slow brain potentials related to motor preparation and stimulus anticipation in a time estimation task. Electroencephalography and Clinical Neurophysiology, 69, 234-243.

Callejas, A., Lupiàñez, J., Funes, M. J., \& Tudela, P. (2005). Modulations among the alerting, orienting and executive control networks. Experimental Brain Research, 167(1), 27-37, http://dx.doi.org/10.1007/s00221-005-2365-z.

Callejas, A., Lupiáñez, J., \& Tudela, P. (2004). The three attentional networks: On their independence and interactions. Brain and Cognition, 54(3), 225-227, http: //dx.doi.org/10.1016/j.bandc.2004.02.012.

Čeponien, R., Yaguchi, K., Shestakova, A., Alku, P., Suominen, K., \& Näätänen, R. (2002). Sound complexity and 'speechness' effects on pre-attentive auditory discrimination in children. International Journal of Psychophysiology, 43(3), 199-211, http://dx.doi.org/10.1016/S0167-8760(01)00172-6.

Chen, S., \& Melara, R. D. (2009). Sequential effects in the simon task: Conflict adaptation or feature integration? Brain Research, 1297(0), 89-100 0.1016/j brainres.2009.08.003.

Chica, A. B., \& Lupiañez, J. (2009). Effects of endogenous and exogenous attention on visual processing: an Inhibition of Return study. Brain Research, 1278, 75-85, http://dx.doi.org/10.1016/j.brainres.2009.04.011.

Coderre, E., Conklin, K., \& van Heuven, W. J. B. (2011). Electrophysiological measures of conflict detection and resolution in the stroop task. Brain Research, 1413, 51-59, http://dx.doi.org/10.1016/j.brainres.2011.07.017.

Corbetta, M., \& Shulman, G. L. (2002). Control of goal-directed and stimulus-driven attention in the brain. Nature Reviews Neuroscience, 3(3), 201-215.

Coull, J. T., Frith, C. D., Büchel, C., \& Nobre, A. C. (2000). Orienting attention in time: Behavioral and neuroanatomical distinction between exogenous and endogenous shifts. Neuropsychologia, 38(6), 808-819, http://dx.doi.org/10.1016/S00283932(99)00132-3.

Curran, T., Hills, A, Patterson, M. B., \& Strauss, M. E. (2001). Effects of aging on visuospatial attention: An ERP study. Neuropsychologia, 39(3), 288-301, http: //dx.doi.org/10.1016/S0028-3932(00)00112-3.

Davidson, M. C., Amso, D., Anderson, L. C., \& Diamond, A. (2006). Development of cognitive control and executive functions from 4 to 13 years: Evidence from manipulations of memory, inhibition, and task switching. Neuropsychologia, 44 (11), 2037-2078, http://dx.doi.org/10.1016/j.neuropsychologia.2006.02.006.

Dosenbach, N. U. F., Fair, D. A., Cohen, A. L., Schlaggar, B. L., \& Petersen, S. E. (2008) A dual-networks architecture of top-down control. Trends in Cognitive Sciences, 12(3), 99-105, http://dx.doi.org/10.1016/j.tics.2008.01.001.

Digiacomo, M. R., Marco-Pallarés, J., Flores, A. B., \& Gómez, C. M. (2008). Wavelet analysis of the EEG during the neurocognitive evaluation of invalidly cued targets. Brain Research, 1234, 94-103, http://dx.doi.org/10.1016/j.brainres 2008.07.072.

Eriksen, B. A., \& Eriksen, C. W. (1974). Effects of noise letters upon the identification of a target letter in a nonsearch task. Perception and Psychophysics, 16(1), 143-149.

Fair, D. A., Dosenbach, N. U. F., Church, J. A., Cohen, A. L., Brahmbhatt, S., \& Miezin, F. M. (2007). Development of distinct control networks through segregation and integration. PNAS Proceedings of the National Academy of Sciences of the United States of America, 104(33), 13507-13512.

Fan, J., Gu, X., Guise, K. G., Liu, X., Fossella, J., Wang, H., et al. (2009). Testing the behavioral interaction and integration of attentional networks. Brain and Cognition, 70(2), 209-220, http://dx.doi.org/10.1016/j.bandc.2009.02.002.

Fan, J., Kolster, R., Ghajar, J., Suh, M., Knight, R. T., Sarkar, R., et al. (2007). Response anticipation and response conflict: An event-related potential and functional magnetic resonance imaging study. Journal of Neuroscience, 27(9), 2272-2282, http://dx.doi.org/10.1523/JNEUROSCI.3470-06.2007.

Fan, J., McCandliss, B. D., Fossella, J., Flombaum, J. I., \& Posner, M. I. (2005). The activation of attentional networks. Neuroimage, 26(2), 471-479, http://dx.doi. org/10.1016/j.neuroimage.2005.02.004.

Fan, J., McCandliss, B. D., Sommer, T., Raz, A., \& Posner, M. I. (2002). Testing the efficiency and independence of attentional networks. Journal of Cognitive Neuroscience, 14(3), 340-347, http://dx.doi.org/10.1162/089892902317361886.

Fan, J., Wu, Y., Fossella, J. A., \& Posner, M. I. (2001). Assessing the heritability of attentional networks. BMC Neuroscience, 2(14), http://dx.doi.org/10.1186/14712202-2-14.

Fjell, A. M., Walhovd, K. B., Brown, T., Kuperman, J. M., Chung, Y., Hagler, D. J., Jr et al. (2012). Multimodal imaging of the self-regulating developing brain. Proceedings of the National Academy of Science of the United States of America, 109(48), 19620-19625, http://dx.doi.org/10.1073/pnas.1208243109.
Flores, A. B., Gómez, C. M., \& Meneres, S. (2010). Evaluation of spatial validityinvalidity by the P300 component in children and young adults. Brain Research Bulletin, 81(6), 525-533, http://dx.doi.org/10.1016/j.brainresbull.2010.01.005.

Goldberg, M. C., Maurer, D., \& Lewis, T. L. (2001). Developmental changes in attention: The effects of endogenous cueing and of distractors. Developmental Science, 4(2), 209-219.

Gómez, C. M., Flores, A., Digiacomo, M. R., Ledesma, A., \& González-Rosa, J. (2008). $\mathrm{P} 3 \mathrm{a}$ and $\mathrm{P} 3 \mathrm{~b}$ components associated to the neurocognitive evaluation of invalidly cued targets. Neuroscience Letters, 430(2), 181-185, http://dx.doi.org/ 10.1016/j.neulet.2007.10.049.

Gómez, C. M., Vaquero, E., \& Vázquez-Marrufo, M. (2004). A neurocognitive model for short-term sensory and motor preparatory activity in humans. Psycologica, 25(2), 217-229.

Hämmerer, D., Li, S.-C., Müller, V., \& Lindenberger, U. (2010). An electrophysiological study of response conflict processing across the lifespan: Assessing the roles of conflict monitoring, cue utilization, response anticipation, and response suppression. Neuropsychologia, 48(11), 3305-3316, http://dx.doi.org/10.1016/j. neuropsychologia.2010.07.014.

Hegerl, U., \& Juckel, G. (1993). Intensity dependence of auditory evoked potentials as an indicator of central serotonergic neurotransmission: A new hypothesis. Biological Psychiatry, 33(3), 173-187, http://dx.doi.org/10.1016/0006-3223(93) 90137-3.

Jennings, J. M., Dagenbach, D., Engle, C. M., \& Funke, L. J. (2007). Age-related changes and the attention network task: An examination of alerting, orienting, and executive function. Aging, Neuropsychology, and Cognition, 14(4), 353-369, http://dx.doi.org/10.1080/13825580600788837.

Jonkman, L. M. (2006). The development of preparation, conflict monitoring and inhibition from early childhood to young adulthood; a Go/Nogo ERP study. Brain Research, 1097(1), 181-193, http://dx.doi.org/10.1016/j.brainres.2006.04. 064

Jonkman, L. M., Lansbergen, M., \& Stauder, J. E. A. (2003). Developmental differences in behavioral and event-related brain responses associated with response preparation and inhibition in a go/nogo task. Psychophysiology, 40(5), 752-761, http://dx.doi.org/10.1111/1469-8986.00075.

Konrad, K, Neufang, S, Thiel, CM, Specht, K, Hanisch, C, Fan, J, et al. (2005). Development of attentional networks: An fMRI study with children and adults. Neuroimage, 28(2), 429-439, http://dx.doi.org/10.1016/j.neuroimage.2005.06.065.

Ladouceur, C. D., Dahl, R. E., \& Carter, C. S. (2007). Development of action monitoring through adolescence into adulthood: ERP and source localization. Developmental Science, 10(6), 874-891, http://dx.doi.org/10.1111/j.14677687.2007.00639.x.

Lamm, C., Zelazo, P. D., \& Lewis, M. D. (2006). Neural correlates of cognitive control in childhood and adolescence: Disentangling the contributions of age and executive function. Neuropsychologia, 44(11), 2139-2148, http://dx.doi.org/ 10.1016/j.neuropsychologia.2005.10.013.

Larson, M. J., Kaufman, D. A. S., \& Perlstein, W. M. (2009). Neural time course of conflict adaptation effects on the stroop task. Neuropsychologia, 47(3), 663-670, http://dx.doi.org/10.1016/j.neuropsychologia.2008.11.013.

Lewis, M. D., \& Todd, R. M. (2007). The self-regulating brain: Cortical-subcortical feedback and the development of intelligent action. Cognitive Development, 22 (4), 406-430, http://dx.doi.org/10.1016/j.cogdev.2007.08.004.

Liotti, M., Woldorff, M. G., Perez, R., III, \& Mayberg, H. S. (2000). An ERP study of the temporal course of the stroop color-word interference effect. Neuropsychologia, 38(5), 701-711, http://dx.doi.org/10.1016/S0028-3932(99)00106-2.

Lorenzo-López, L., Doallo, S., Vizoso, C., Amenedo, E., Rodríguez Holguín, S., \& Cadaveira, F. (2002). Covert orienting of visuospatial attention in the early stages of aging. Neuroreport, 13(11), 1459-1462.

Loveless, N. E., \& Sanford, A. J. (1974). Effects of age on the contingent negative variation and preparatory set in a reaction time task. Journals of Gerontology, 29(1), $52-63$.

Luck, S. J., \& Hillyard, S. A. (1995). The role of attention in feature detection and conjunction discrimination: An electrophysiological analysis. International Journal of Neuroscience, 80, 281-297.

Mangun, G. R. (1995). Neural mechanisms of visual selective attention. Psychophysiology, 32(1), 4-18.

Mangun, G. R., Hansen, J. C., \& Hillyard, S. A. (1986). Electroretinograms reveal no evidence for centrifugal modulation of retinal inputs during selective attention in man. Psychophysiology, 23(2), 156-165.

Mangun, G. R. R., \& Hillyard, S. A. (1987). The spatial allocation of visual attention as indexed by event-related brain potentials. Human Factors, 29(2), 195-211.

Mangun, G. R., \& Hillyard, S. A. (1991). Modulations of sensory-evoked brain potentials indicate changes in perceptual processing during visual-spatial priming. Journal of Experimental Psychology: Human Perception and Performance, 17(4), 1057-1074, http://dx.doi.org/10.1037/0096-1523.17.4.1057.

Mezzacappa, E. (2004). Alerting, orienting, and executive attention: Developmental properties and sociodemographic correlates in an epidemiological sample of young, urban children. Child Development, 75(5), 1373-1386, http://dx.doi.org/ 10.1111/j.1467-8624.2004.00746.x.

Morrison, F. J. (1982). The development of alertness. Journal of Experimental Child Psychology, 34(2), 187-199, http://dx.doi.org/10.1016/0022-0965(82)90041-8.

Perchet, C., \& García-Larrea, L. (2000). Visuospatial attention and motor reaction in children: An electrophysiological study of the 'posner' paradigm. Psychophysiology, 37(2), 231-241, http://dx.doi.org/10.1017/S0048577200981368.

Perlstein, W. M., Larson, M. J., Dotson, V. M., \& Kelly, K. G. (2006). Temporal dissociation of components of cognitive control dysfunction in severe TBI: ERPs 
and the cued-stroop task. Neuropsychologia, 44(2), 260-274, http://dx.doi.org/ 10.1016/j.neuropsychologia.2005.05.009.

Petersen, S. E., \& Posner, M. I. (2012). The Attention System of the Human Brain: 20 Years After. Annual Review of Neuroscience, 35(1), 73-89, http://dx.doi.org/ 10.1146/annurev-neuro-062111-150525.

Picton, T. W., Hillyard, S. A., Krausz, H. I., \& Galambos, R. (1974). Human auditory evoked potentials. I: Evaluation of components. Electroencephalography and Clinical Neurophysiology, 36, 179-190, http://dx.doi.org/10.1016/0013-4694(74)90155-2.

Ponton, C. W., Don, M., Eggermont, J. J., Waring, M. D., \& Masuda, A. (1996) Maturation of human cortical auditory function: Differences between normalhearing children and children with cochlear implants. Ear and Hearing, 17(5), 430-437, http://dx.doi.org/10.1097/00003446-199610000-00009.

Ponton, C. W., Eggermont, J. J., Kwong, B., \& Don, M. (2000). Maturation of human central auditory system activity: Evidence from multi-channel evoked potentials. Clinical Neurophysiology, 111(2), 220-236, http://dx.doi.org/10.1016/ S1388-2457(99)00236-9.

Posner, M. I. (1980). Orienting of attention. The Quarterly Journal of Experimental Psychology, 32(1), 3-25.

Posner, M. I. (1994). Attention: The mechanism of consciousness. Proceedings of the National Academy of Science of the United States of America, 91, 7398-7403, http: //dx.doi.org/10.1073/pnas.91.16.7398.

Posner, M. I., \& Cohen, Y. (1984). Components of visual orienting. In: H. Bouma, \& D. Bouwhuis (Eds.), Attention and performance X (pp. 531-556). London: Lawrence Erlbaum.

Posner, M. I., \& Petersen, S. E. (1990). The attention system of the human brain. Annual Review of Neuroscience, 13, 25-42.

Posner, M. I., Rothbart, M. K., Sheese, B., \& Tang, Y. (2007). The anterior cingulate gyrus and the mechanismself-regulation. Cognitive, Affective $\mathcal{E}$ Behavioral Neuroscience, 7(4), 391-395, http://dx.doi.org/10.3758/CABN.7.4.391.

Posner, M. I., Rothbart, M. K., Vizueta, N., Levy, K. N., Evans, D. E., Thomas, K. M. et al. (2002). Attentional mechanisms of borderline personality disorder. Proceedings of the National Academy of Sciences of the United States of America, 99(25), 16366-16370, http://dx.doi.org/10.1073/pnas.252644699.

Posner, M. I., Rueda, M. R. \& Kanske, P. (2007). Probing the mechanisms of attention. In: J. T. Cacioppo, J. G. Tassinary, \& G. G. Berntson (Eds.), Handbook of psychophysiology (3rd ed.). Cambridge, UK: Cambridge University Press.

Pozuelos, J. P., Paz-Alonso, P. M., Castillo, A., Fuentes, L. J., \& Rueda, M. R. Development of attention networks and their interactions inchildhood, under review.

Ridderinkhof, K. R., \& van der Molen, M. W. (1995). A psychophysiological analysis of developmental differences in the ability to resist interference. Child Development, 66 (4), 1040-1056, http://dx.doi.org/10.1111/j.1467-8624.1995.tb00921.x.

Ritter, W., Simson, R., Vaughan, H. G., Jr., \& Macht, M. (1982). Manipulation of eventrelated potential manifestations of information processing stages. Science, 218 (4575), 906-909.

Rueda, M. R. (2013). Development of attention. In: K. Ochsner, \& S. Kosslyn (Eds.), Oxford handbook of cognitive neuroscience (pp. 296-318). New York: Oxford University Press.

Rueda, M. R., Fan, J., McCandliss, B. D., Halparin, J. D., Gruber, D. B., Lercari, L. P., et al. (2004). Development of attentional networks in childhood. Neuropsychologia, 42(8), 1029-1040, http://dx.doi.org/10.1016/j.neuropsychologia.2003.12.012.

Rueda, M. R., Posner, M. I., \& Rothbart, M. K. (2005). The development of executive attention: Contributions to the emergence of self-regulation. Developmental Neuropsychology, 28(2), 573-594, http://dx.doi.org/10.1207/s15326942dn 2802_2.
Rueda, M. R., Posner, M. I., Rothbart, M. K., \& Davis-Stober, C. P. (2004). Development of the time course for processing conflict: An event-related potentials study with 4 year olds and adults. BMC Neuroscience, 5(39), http://dx.doi.org/ 10.1186/1471.2202-5-39.

Schul, R., Townsend, J., \& Stiles, J. (2003). The development of attentional orienting during the school-age years. Developmental Science, 6(3), 262-272, http://dx. doi.org/10.1111/1467-7687.00282.

Segalowitz, S. J., \& Davies, P. L. (2004). Charting the maturation of the frontal lobe: An electrophysiological strategy. Brain and Cognition, 55(1), 116-133, http://dx. doi.org/10.1016/S0278-2626(03)00283-5.

Sharma, A., Kraus, N., J. McGee, T., \& Nicol, T. G. (1997). Developmental changes in P1 and N1 central auditory responses elicited by consonant-vowel syllables. Electroencephalography and Clinical Neurophysiology, 104(6), 540-545, http://dx doi.org/10.1016/S0168-5597(97)00050-6.

Stieben, J., Lewis, M. D., Granic, I., Zelazo, P. D., Sealowirz, S., \& Pepler, D. (2007) Neurophysiological mechanisms of emotion regulation for subtypes of externalizing children. Development and Psychopathology, 19(2), 455-480, http://dx doi.org/10.1017/S0954579407070228.

Tucker, D. M., Liotti, M., Potts, G. F., Russell, G. S., \& Posner, M. I. (1993) Spatiotemporal analysis of brain electrical fields. Human Brain Mapping, 1(2), $134-152$.

van Veen, V., \& Carter, C. S. (2002). The anterior cingulate as a conflict monitor: FMRI and ERP studies. Physiological Behavior, 77(4-5), 477-482, http://dx.doi. org/10.1016/S0031-9384(02)00930-7.

Vogel, E. K., \& Luck, S. J. (2000). The visual N1 component as an index of a discrimination process. Psychophysiology, 37(2), 190-203, http://dx.doi.org/ 10.1017/S0048577200981265.

Wainwright, A., \& Bryson, S. E. (2002). The development of exogenous orienting: Mechanisms of control. Journal of Experimental Child Psychology, 82(2), 141-155, http://dx.doi.org/10.1016/S0022-0965(02)00002-4.

Wainwright, A., \& Bryson, S. E. (2005). The development of endogenous orienting: Control over the scope of attention and lateral asymmetries. Developmental Neuropsychology, 27(2), 237-255, http://dx.doi.org/10.1207/s15326942dn 2702_3.

Walter, W. G., Cooper, R., Aldridge, V. J., McCallum, W. C., \& Winter, A. L. (1964) Contingent Negative Variation: An electric sign of sensorimotor association and expectancy in the human brain. Nature, 203, 380-384, http://dx.doi.org/ $10.1038 / 203380 \mathrm{a} 0$.

Waszak, F. (2010). Across-task long-term priming: Interaction of task readiness and automatic retrieval. Quarterly Journal of Experimental Psychology, 63(7), 1414-1429, http://dx.doi.org/10.1080/17470210903414373.

Waszak, F., Li, S. C., \& Hommel, B. (2010). The development of attentional networks: Cross-sectional findings from a life span sample. Developmental Psychology, 46 (2), 337-349, http://dx.doi.org/10.1037/a0018541.

Weinbach, N., \& Henik, A. (2012). The relationship between alertness and executive control. Journal of Experimental Psychology: Human Perception and Performance 38(6), 1530-1540, http://dx.doi.org/10.1037/a0027875.

West, R. (2003). Neural correlates of cognitive control and conflict detection in the Stroop and digit-location tasks. Neuropsychologia, 41(8), 1122-1135, http://dx. doi.org/10.1016/S0028-3932(02)00297-X.

West, R., \& Alain, C. (2000). Effects of task context and fluctuations of attention on neural activity supporting performance of the stroop task. Brain Research, 873 (1), 102-111, http://dx.doi.org/10.1016/S0006-8993(00)02530-0. 